\title{
THE WOMAN IN THE NOVELS OF SAAD MOHAMMED RAHEEM
}

\author{
Ihsan Hussain ZUBAID ${ }^{1}$
}

\section{Istanbul / Türkiye \\ p. $432-446$}

Received: 03/12/2021

Accepted: $19 / 12 / 2021$

Published: 01/01/2022

This article has been scanned I iThenticat No plagiarism detected

\begin{abstract}
:
Women suffered - and as soon as they were removed - from the sway of the patriarchal society, the domination of men over them and their denial of achieving their independence, and the failure to take their opinion on fateful decisions such as marriage, education, and work, and that the novels of (Saad Muhammad Rahim) shed light on these problems and other inferiority of their role. In public life, in addition to the appearance of women in the society of novels (the research material) in a stereotypical manner, as these novels did not give a good space for women - Arab and Western - thought, literature and culture, while his body recorded the presence of femininity in the presence of a valuable cultural sting, revealing the patriarchal view Towards the woman.
\end{abstract}

Key words: Women, Body, Love, Culture, Gender, Dominance.

http://dx.doi.org/10.47832/2717-8293.15.31 
المرأة في روايات سعد محمد رحيم

\section{إحسان ناصر حسين الزبيدي 2}

الملخص:

عانت المرأة -ولمكا تزل- من سطوة المجتمع الذكوري، وهيمنة الرجل عليها وحرماها من تحقيق استقلاليتها، وعدم

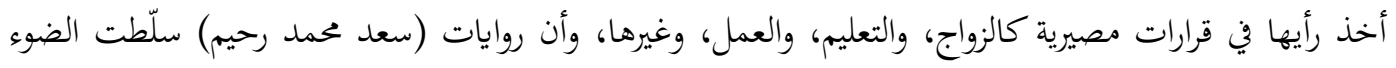

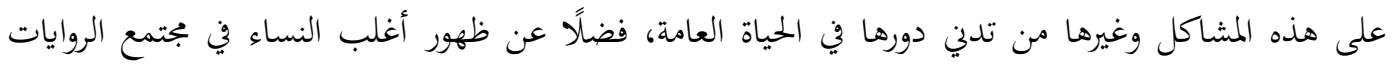
(مادّة البحث) بصورة نمطية، كما لم تمنح هذه الروايات مساحة جيدة لفكر المرأة العربية والغربية وأدها وثقافتها،

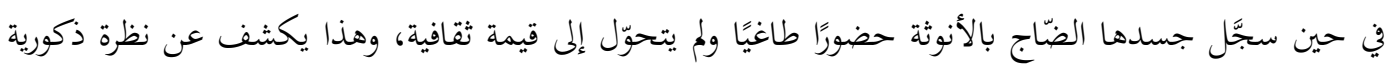
تجاه المرأة، الكلمات المفتاحية: المرأة، الجسد، الحبّ، الثقافة، الجنس، المهيمنة.

قضية المرأة في الأدب عامة قضية في غاية الأهمية، نظرًا للدور الكبير الذي باتت تؤديه في المجتمع، فضلًا عن كوها واحدة

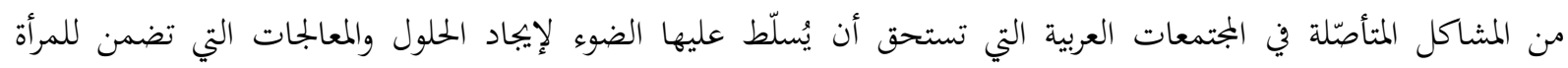

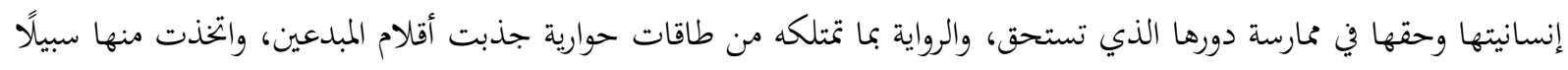
لمعالجة الكثير من قضايا الفرد والمجتمع. ولاسيما تلك التي يصعب التصريح بها، فقد انفتح السرد الروائي على عالم المرأة، وعالج قضايا تمسَّها مثل: الحبِّ، والكره، والزواج، والطلاق، ودور المرأة في المجتمع وعلاقتها بالرجل، فضلاً عن معالجة أوضاعها الجنسية، والثقافية، والنفسية، والاقتصادية.

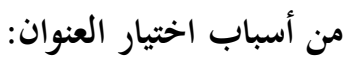

يُعد (سعد محمد رحيم) من الروائين الذين عالجوا قضية المرأة ومنحوها مساحة مهمة في كتاباقم، ولعلّ حضور المرأة في

متون رواياته بات ثيمة وعلامة فارقة تميزّ أعماله الروائية، ومن هنا جاءت هذه الدراسة للكشف عن وضع المرأة العراقية، وغيرها في

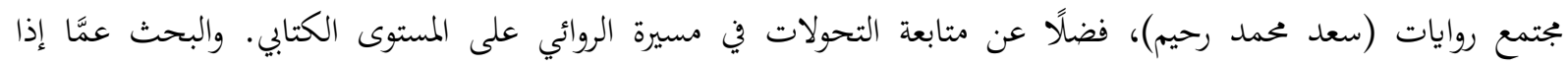

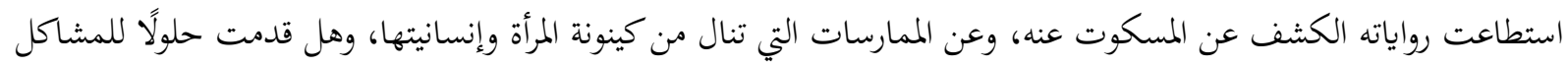

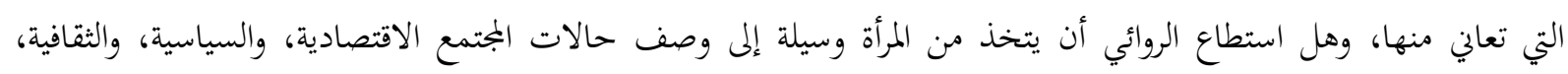
والاجتماعية. 


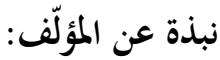

سعد محمد رحيم (1957 - 2018) كاتب عراقي، عمل في الصحافة والتدريس، صدرت له ست مجموعات قصصية،

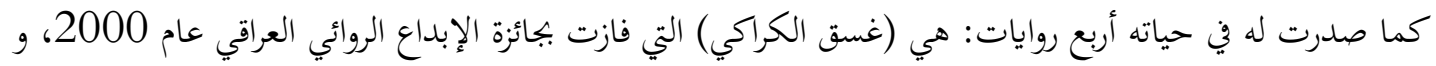

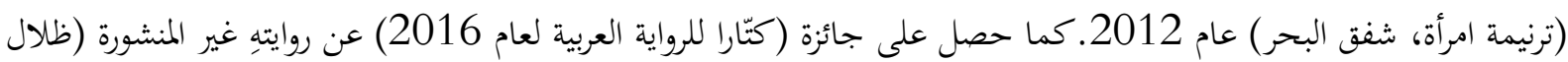
جسد، ضفاف الرغبة)، وصدرت له عام 2017 رواية (مقتل بائع الكتب) التي وصلت إلى القائمة القصيرة لجائزة البوكر العربية،

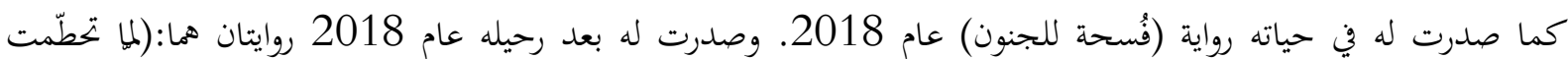

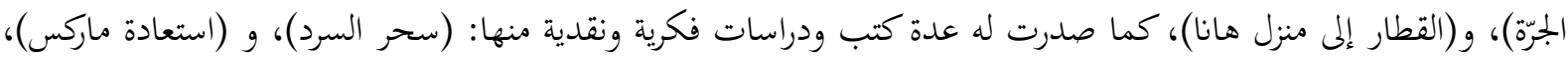
و (المثقف الذي يدس أنفه).

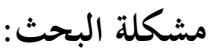

لا جدالَ في أنَّ أيّ بلد لن يستطيع تطوير نفسه ما لم تأخذ المرأة فيه مكانتها، ويُفسح لها المجال لأخذ دورها في عملية

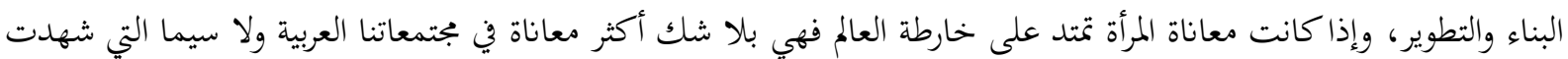
تحولات سياسية وأزمات اقتصادية ومنها المجتمع العراقي. إذ لم تحصل المرأة على أبسط حقوقها التي تضمن لها إنسانيتها وتحقق

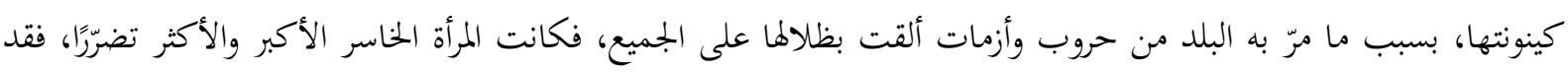

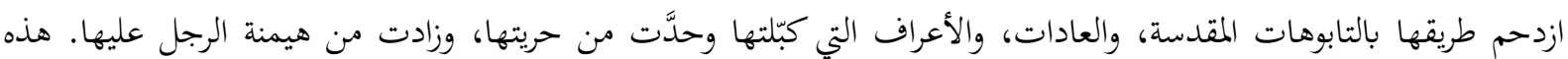
المشكلة تناولما الروائي (سعد محمد رحيم) وسلّط الضوء عليها في رواياته ليكشف حجم الظمات الظلم الذي لحق بالمرأة والمعاناة الكبيرة

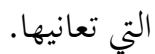

\section{المنهج المتّبع:}

هو المنهج الوصفي التحليلي الذي يسمح للباحث توصيف مشكلات البحث بدقة، والوصول لاستنتاجات علمية على وفق الشواهد التي يتضمّنها البحث بعيدًا عن التحيّز الشخصي.كما يسمح بتسليط الضوء على الأمراض الثقافية، والأنساق

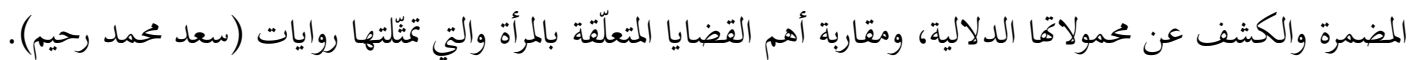

\section{أنماط المرأة وتجلياتما في روايات (سعد محمد رحيم).}

الأم، هي ينبوع المحبة المتدفق، والكوكب الدري الذي يبعث للقلوب أشعة العطف، والإيثار، والعطاء، لذا يُفترض بها أن

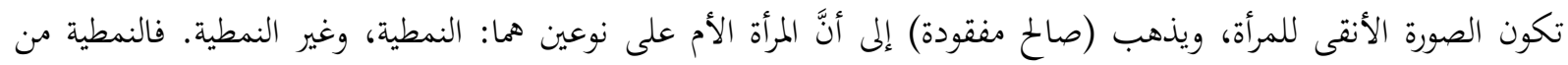

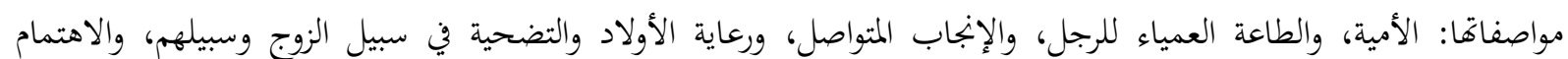
بشؤون المنزل، وعدم الخروج منه إلا بإذن الرجل (مفقوده، 2009). وذهبت (إمان القاضي) إلى توصيف المرأة النمطية بقوها:

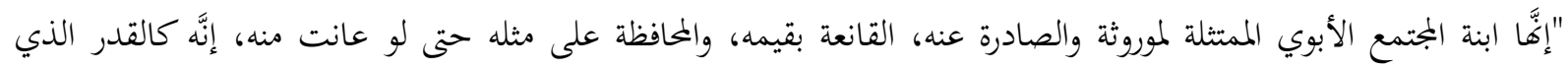

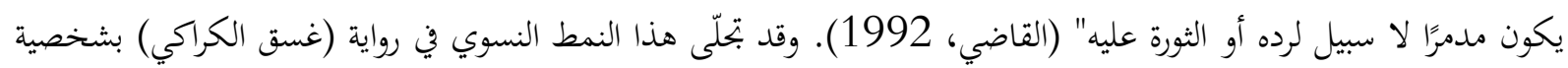

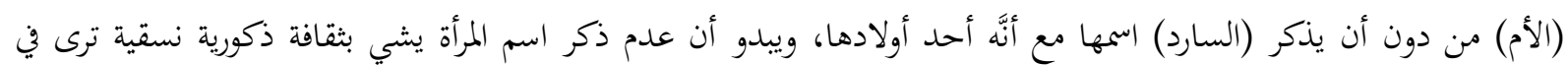


كما أنَّ عدم ذكر الاسم بوجه عام أو مصادرته إنما ينطوي على دلالة بعيدة تكمن في التقليل من قيمة الشخص والنزول بكينونته إلى درك من الدونية (بحراوي، 1990)، فضلًا عن أنّ اخفاء الاسم فيه إشارة إلى عمومية الحالة. هذه الأم امرأة بسيطة تؤمن بالخرافات، وتلبّس الشياطين بالبشر، وتلجأ إلى الغيبيات والقيام ببعض الطقوس البدائية، لطرد الحسد والجن عن أفراء الفراد عائلتها (رحيم، غسق الكراكي، 2017)

ويبدو أنَّ من أسباب تكريس دونيّة المرأة "اعتمادها اقتصاديا على الرجل وحالة الجهل التي كانت تعيشها، إلى جانب

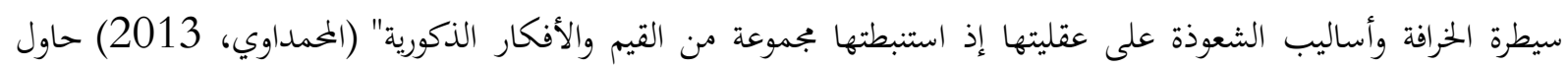
(السارد) أن يظهرها بصورة امرأة زاهدة وقور، وصلدة، وبهية على الرغم من شيخوختها المبكرة، لكنَّها في الوقت ذاته لا بتحيد عملاً

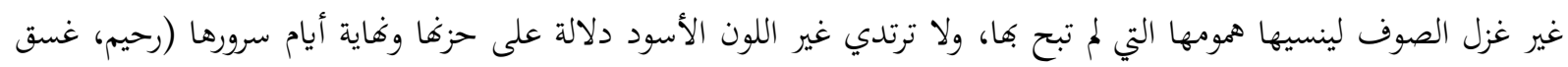

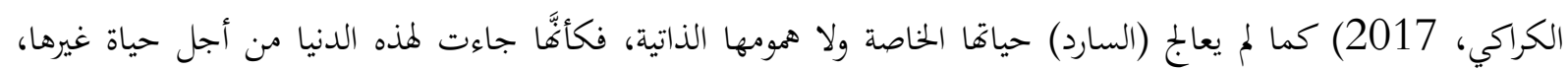

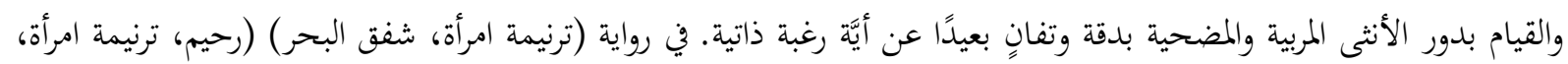

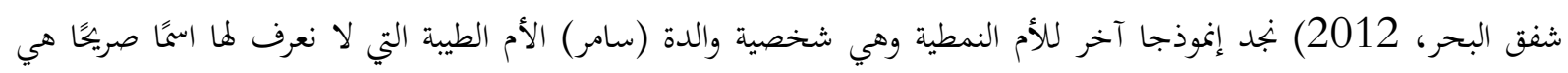

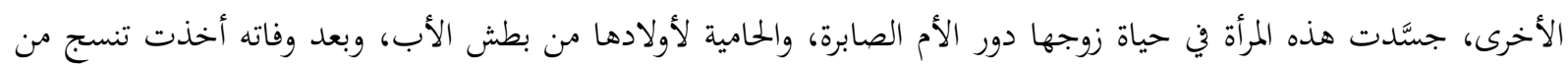

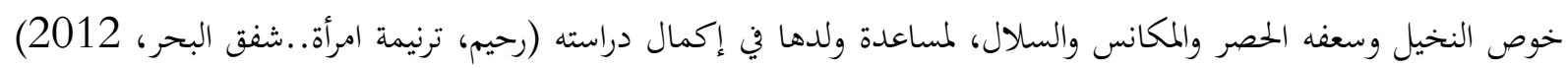

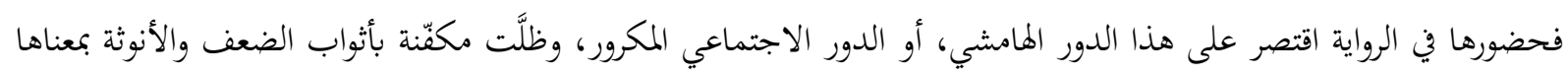

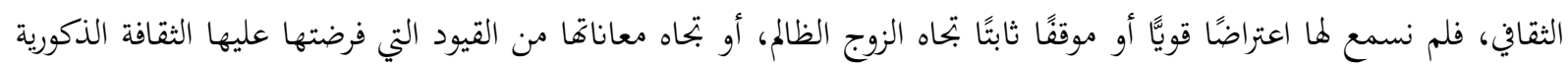

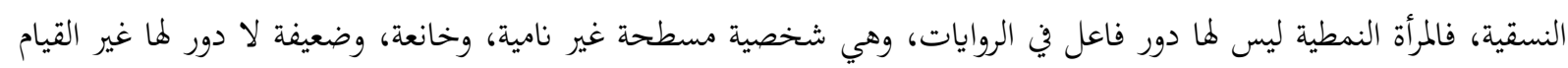

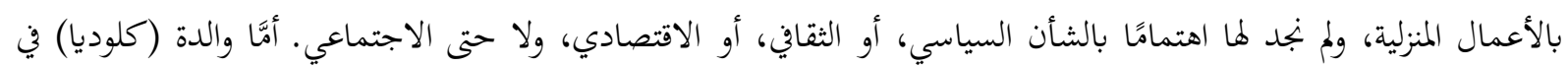
الرواية ذاتما لم تكن

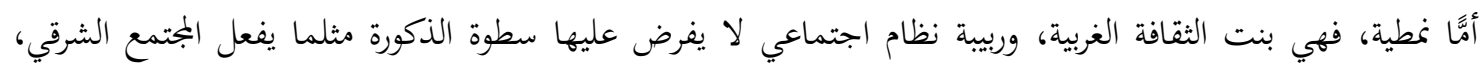

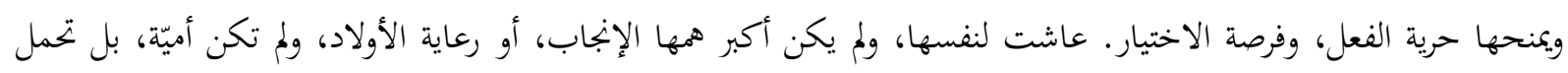

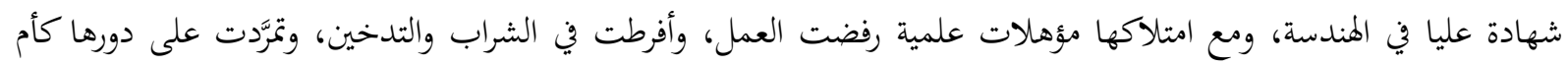
(رحيم، ترنيمة امرأة..شفق البحر، 2012)

من نماذج هذا النمط (سارة) التي لم يُسمح لها أن تستمتع بأيام طفولتها كما ينبغي، فقد منعها أخوها الأكبر -بتوجيه

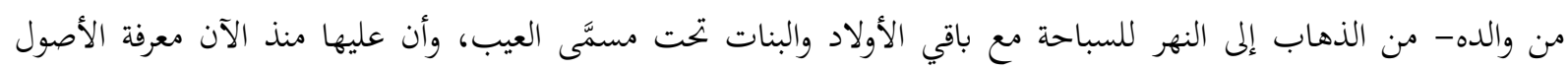
(رحيم، غسق الكراكي، 2017).

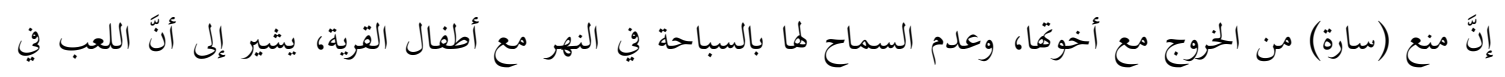

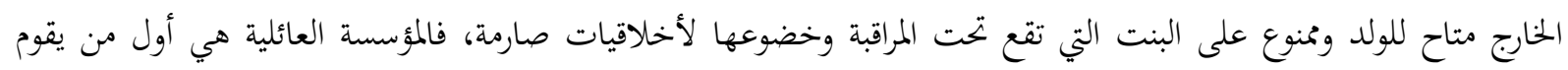

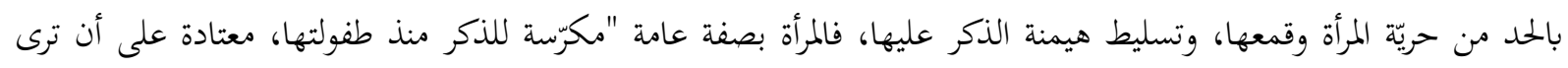

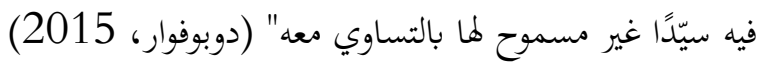
تحصّلت (سارة) على شهادة جامعية ولكنها لم تحصل على فرصة للعمل لإتبات وجودها وتحقيق استقلاليتها وانحسر

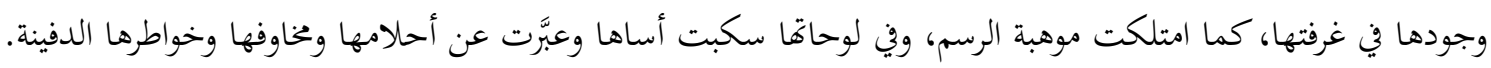


ترك غياها في بغداد خلال سنوات دراستها الجامعية فراغًا كبيرًا في نفوس اخوتها الثلاثة، فقد مثَّت النسغ الحيوي المتصاعد في كيان عائلتها (رحيم، غسق الكراكي، 2017)، وعلى الرغم من كلِّ ذلك وقعت (سارة) الموهوبة والجامعية ضحية أحد زملائها

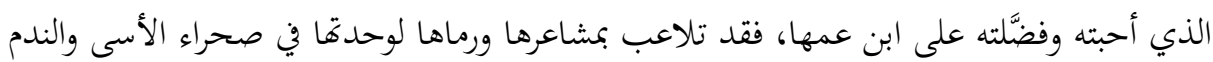
(رحيم، غسق الكراكي، 2017).

ويمكن أن نفهم من قصة (سارة) أنَّ المرأة العربية عمومًا تعيش في أزمة، فحتى المتعلّمة وقعت ضحية لمشاعرها، ولم تحسن

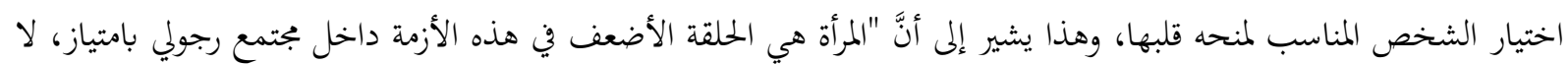

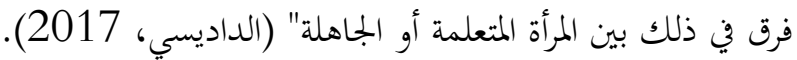

ومن الأمثلة الأخرى على هذا النمط شخصية (شيماء) أخت (سامر) بطل رواية (ترنيمة امرأة، شفق البحر) فقد مثّلت

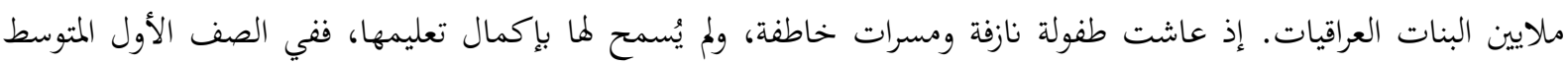

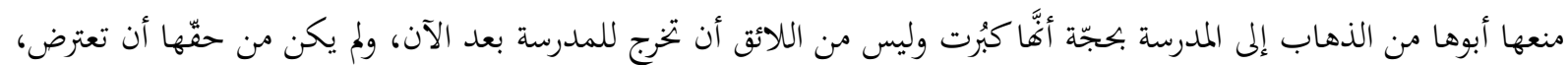

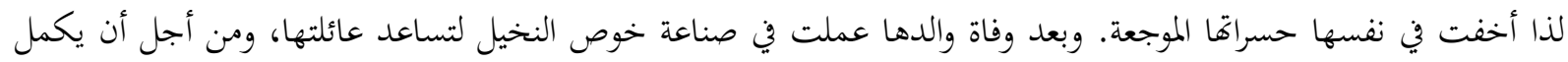

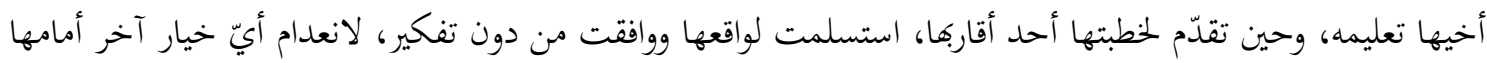
(رحيم، ترنيمة امرأة، شفق البحر، 2012). ولم يختلف حال (علياء) أخت (حكمت/عامر) عن حال سابقاقا، فعلى الرغم من

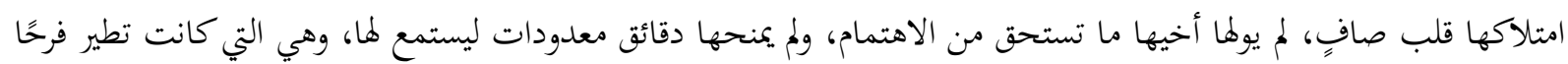

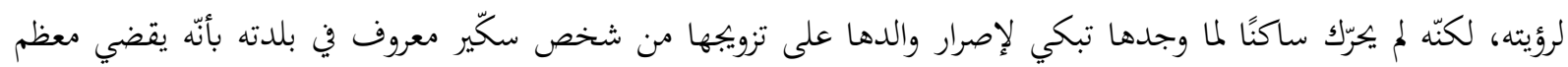

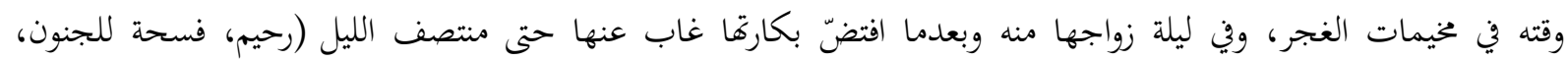

هذه النماذج النسائية بيَّت أن علاقة المرأة بالرجل أقرب ما تكون إلى علاقة السيّد بالعبد أو الجارية، فهي علاقة هيمنة واستسلام، فالرجل هو سيّد الموقف والمرأة تابعة مهمّشة مقموعة، وجاءت في مرتبة دونيّة.

لا شكَّ في أنَّ قضية المرأة بوجه عام من "القضايا القديمة المتجددة أها قضية ملحة ومفتوحة. كثيرا ما تثار بطريقة تصل

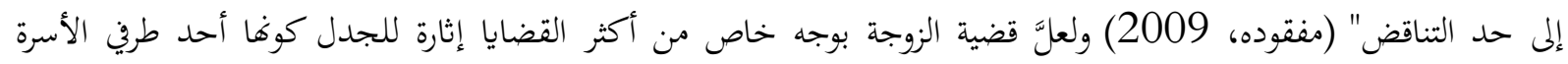

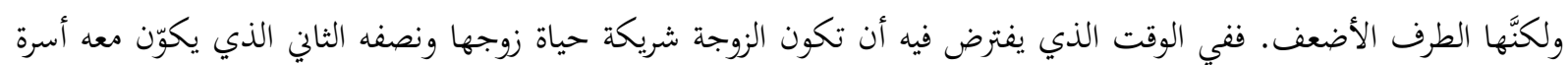

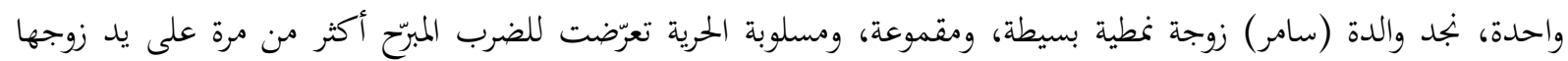

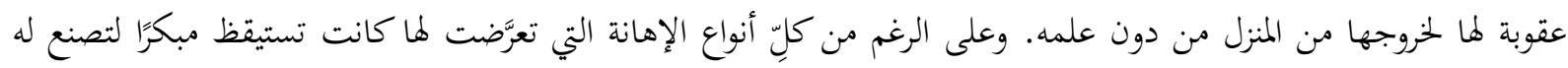

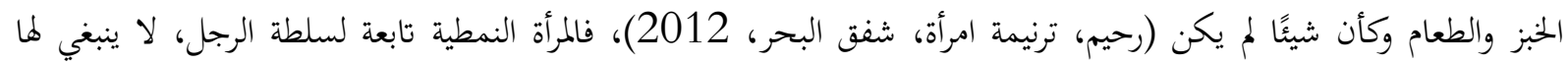

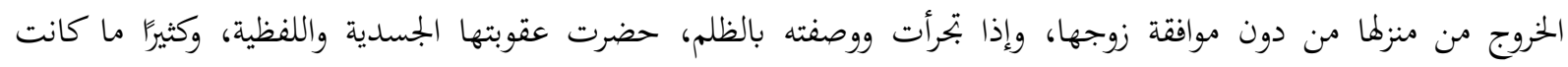
تستقبلها بدموع وصمت. ويبدو أنَّ ضرب الزوجة وسيلة تقليدية لفرض سطوة الزوج وهيمنته، وإحساسه برجولته، وربما يقوم بذلك تنفيسًا عن كبته

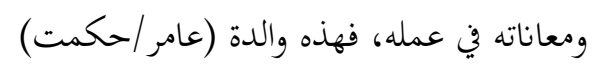
عاملها زوجها العسكري الذي يقضي أيام إجازته سكرانًا معاملة سيئة للغاية وأذاقها الويل على مدى سبع سنين، وكان سببًا غير مباشر لوفاتما في يوم ولادة (عامر/حكمت)، فقد ضرجها بنطاقه العسكري قبل يوم واحد من الولادة (رحيم، فسحة 
للجنون، 2018)، وحين مرضت زوجة الحاج (إبراهيم)، رُميت في غرفتها كخرقة بالية، ولم تكن تتمتّع بأيّة سلطة مادية أو

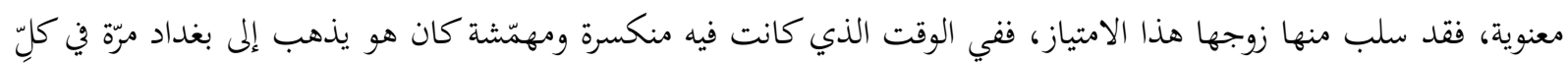

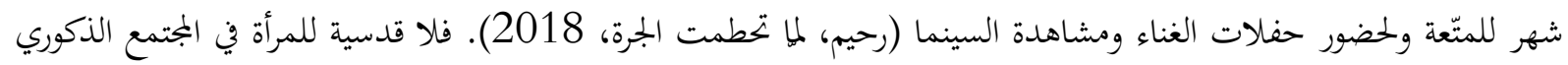

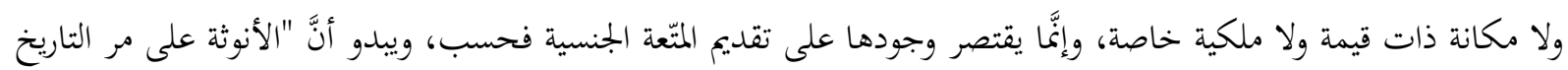

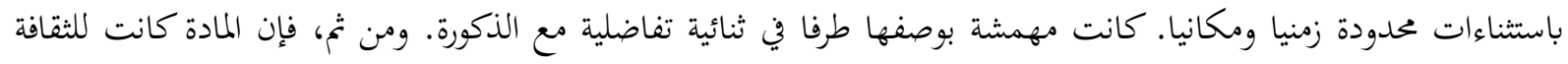
الأبوية على حساب الثقافة الأموية" (عبدالمطلب، 2008)، وفي الرواية ذاتها ظهرت الزوجة غير النمطية أنانية، ومتمرّدة، وغير

أخلاقية، وعلاقتها سيئة بزوجها، ولا تسكت على الإهانة، ولا تنفذ أوامره، ولا تتردد في خيانته، مثالها (عاتكة) هذه الزوجة كانت ترد الشتيمة بالشتيمة، بل وهدّدت زوجها(عادل) بالندم إن بترأ وضربها (رحيم، لما تحطمت الجرة، 2018)، ومع ذلك لم تكن (عاتكة) محل احترام وتقدير من عائلة زوجها، بل كانت تتعرّض للإهانة من أغلب أفراد هذه العائلة،

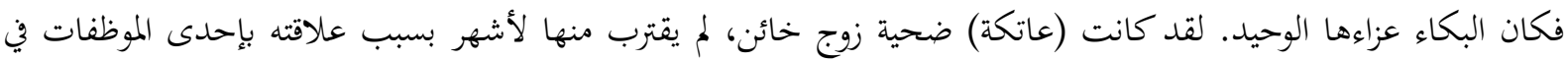

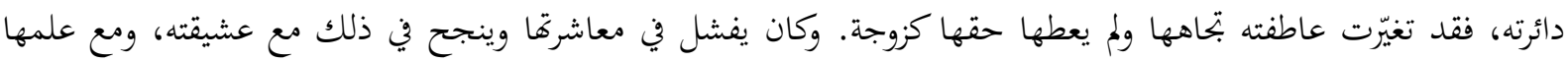

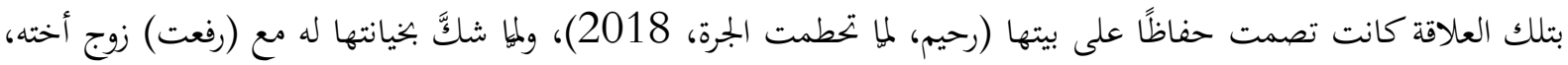

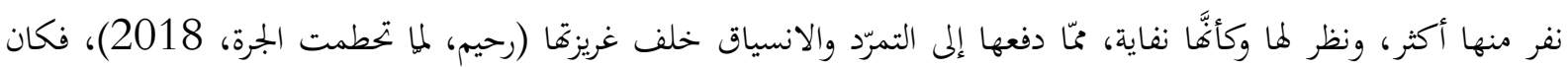

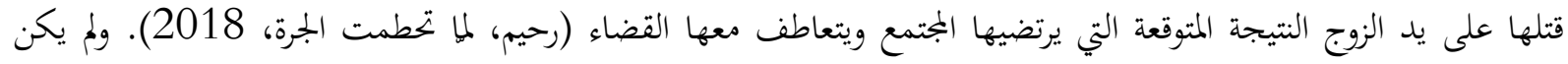

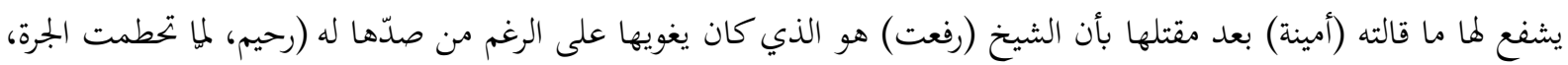

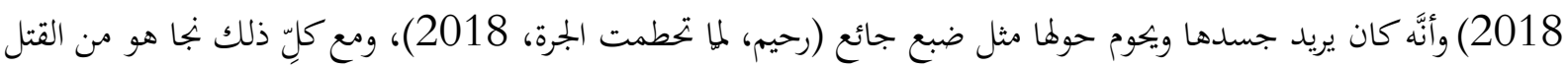

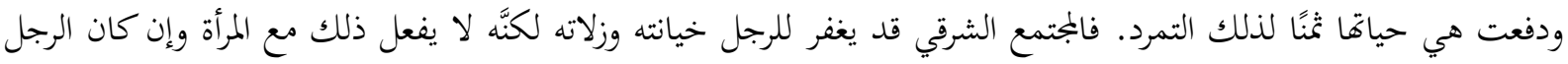

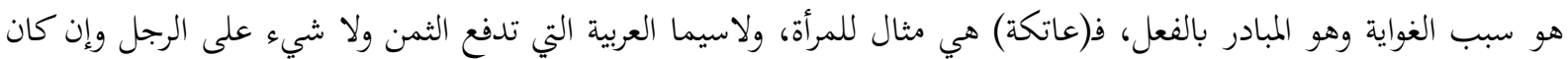
شريكها في الخطيئة.وبحدر الإشارة إلى أنَّ ما قامت به (عاتكة) و(عارف) من خيانة زوجية يشير إلى تحلّ العلاقات الأسرية والاجتماعية وتفسخها وزيفها بعد الغزو الأمريكي للعراق عام 2003، فالرواية بنية أيديولوجية لا يمكنها الانفصال عن التحولات التي يشهدها المجتمع. أَّاّا (نجاة) زوجة الشيخ (رفعت) هي الأخرى ضحية زوجها الخائن المتستر على نزقه وشيطنته بلباس الدين، بعد أن كانت

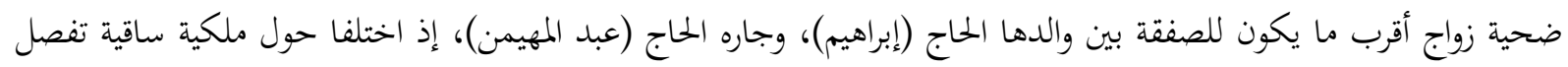

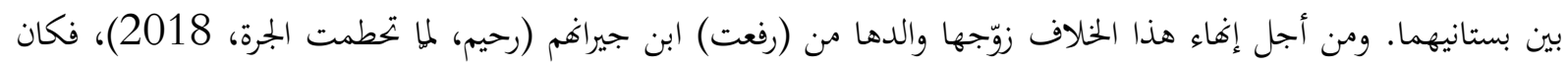

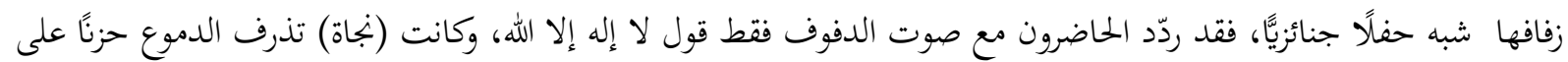

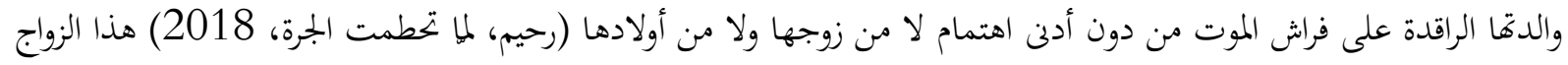
الصفقة الذي يصادر حق المرأة في اختيار شريك حياتا، كانت فايته الخيانة والفشل والضياع، دفع الزوجان ثمنه، ولاسيما (نجاة)

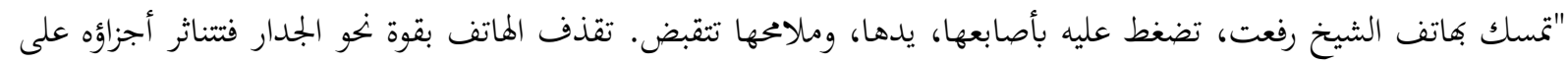

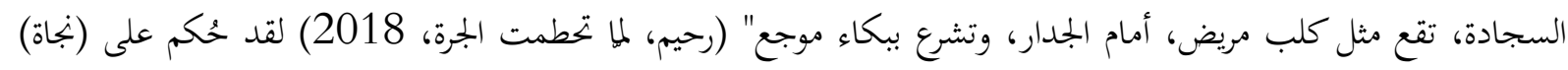

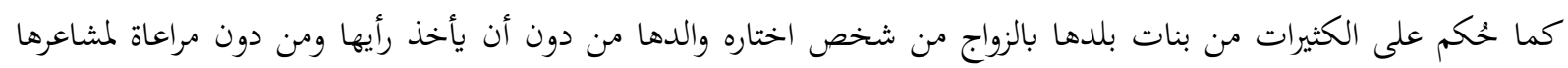
ورغباتما.

أمَّا (أمينة) فقد تزوّجت من الحاج (إبراهيم) وهو الذي يكبرها كثيرًا، لم يُسمعها كلمة (حبيبتي) ولو مرّة واحدة، فهو لا

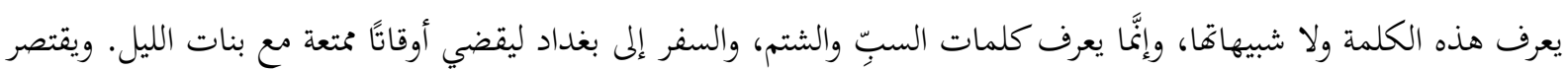

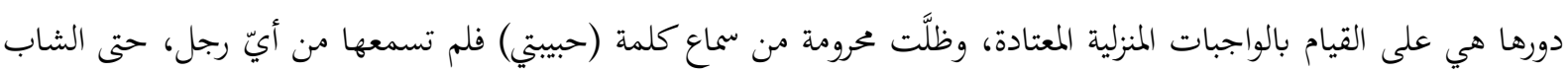


الذي أحبته سابقًا لم يُسمعها عبارات غزل إلّا نادرًا، فقد كان من النوع الذي يكتم مشاعره، ولمها بتركَّأ وأسععها كلاما غزليَّا للمرّة

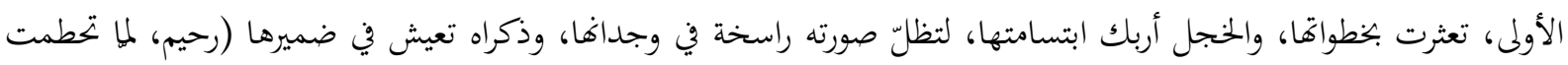

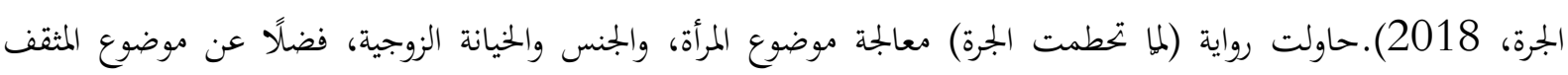

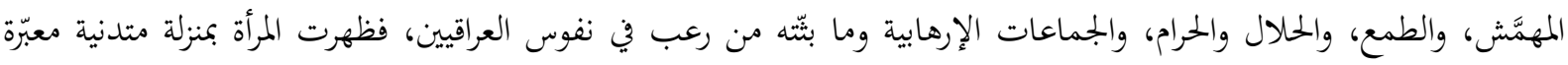
عن واقعها المأزوم، وعن مجتمعها الذكوري الذي يرتضي للرجل ما وال الا يرتضيه لها. يبدو أنَّ الروائي (سعد محمد رحيم) أراد -عبر رواياته- أن يصوّر المرأة، ولاسيما العراقية بمختلف صورها وما تعانيه على يد

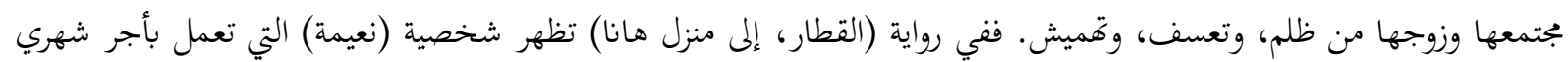

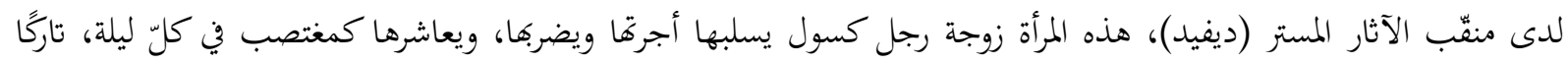

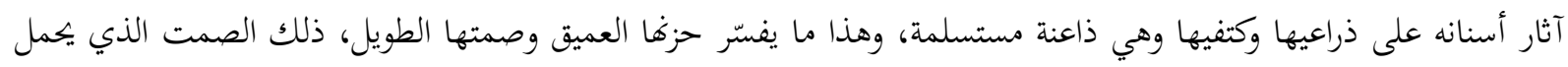

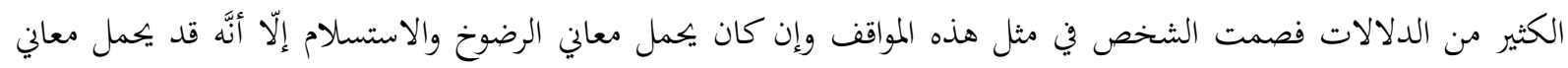

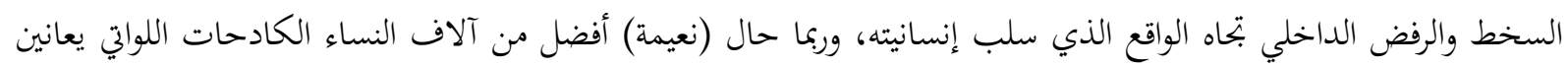
من شتى أنواع الأمراض ويمتن قبل بلوغ الأبعين (رحيم، القطار ..إلى منزل هانا، 2018).

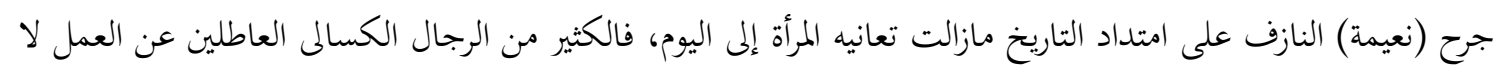

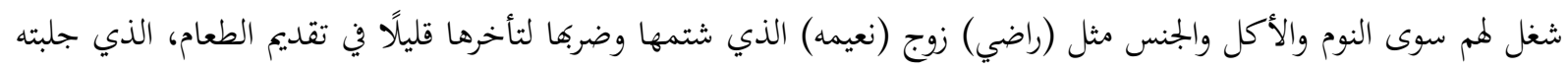

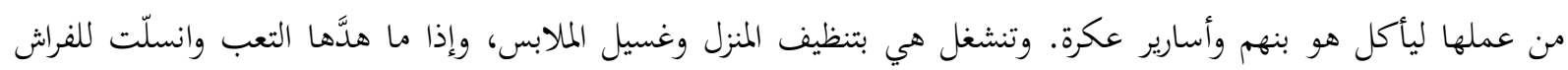

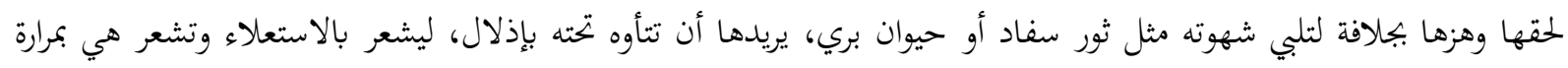

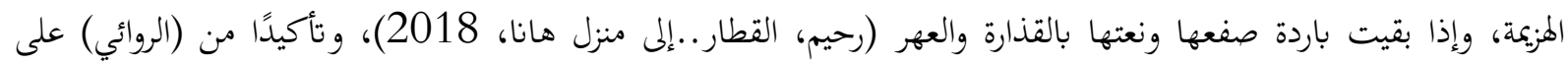

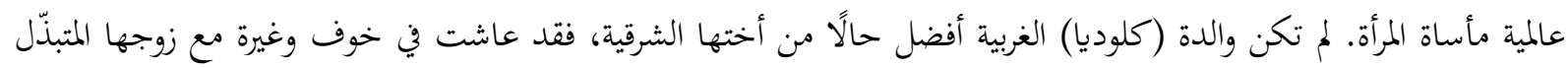

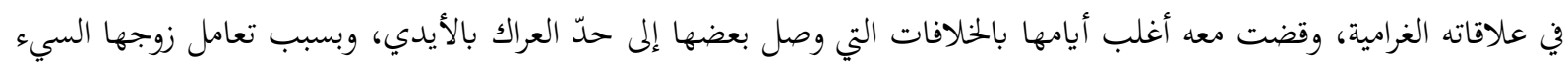
أصاهما المرض، وفقدت رونقها وجمالها. ولم تعد كما كانت ممتازة في فراش الزوجية على حلدِ تعبير زوجها (ألبرتو) (رحيم، ترنيمة

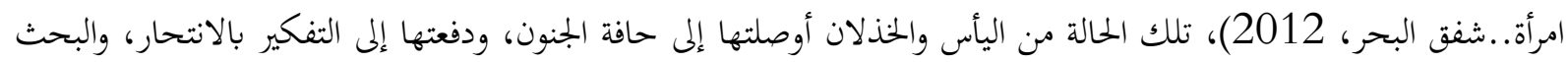

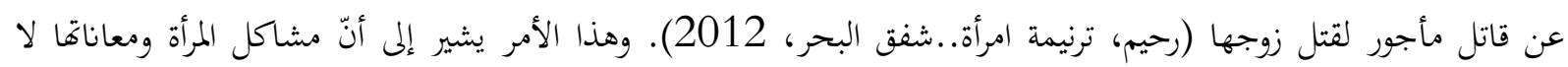

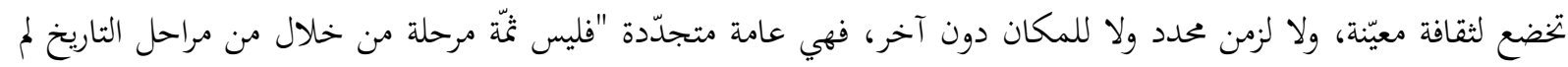

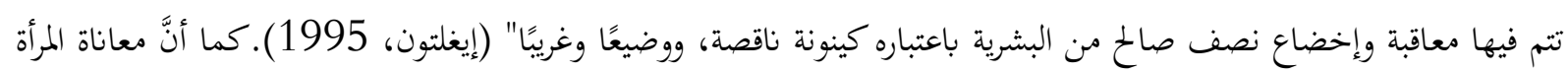

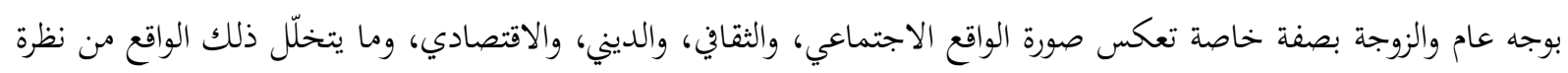

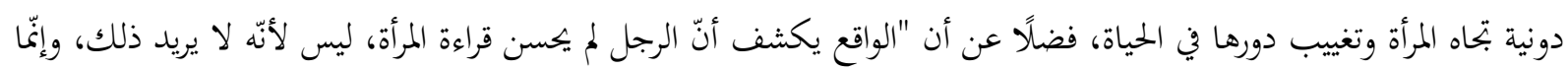

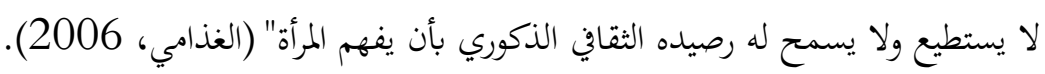

- المرأة الحبيبة قبل الحديث عن المرأة الحبيبة أودُّ أن أشير إلى الفرق الدلالي بين الحبٍّ والجنس "الجنس معطى ملموس مرتبط بالجسد، والحب إحساس هلامي مرتبط بالروح والشعور" (الداديسي، 2017). 


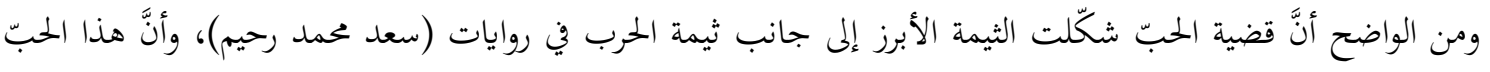

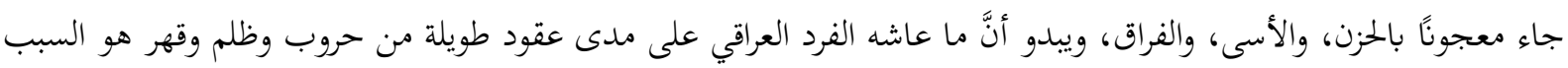

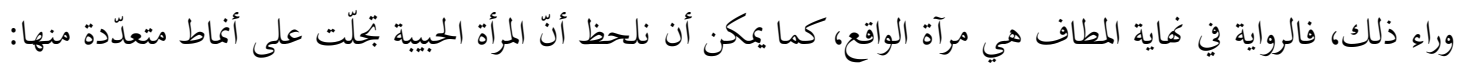

1

من نماذج هذا النمط (كلوديا) وهي فتاة إيطالية، تعرَّف عليها (سامر) على ساحل مدينة (سوسة) التونسية في أثناء تنقّله

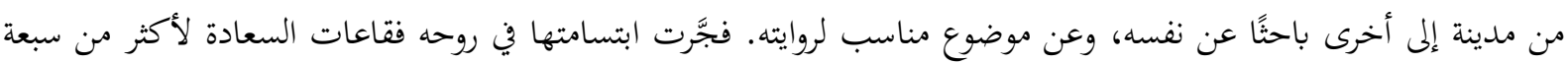

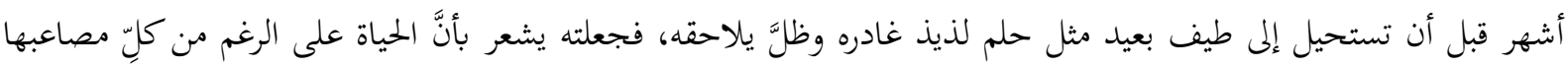

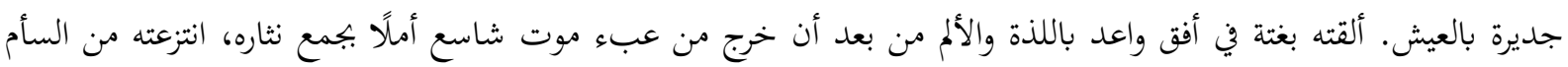
والوحدة واللاجدوى ومنحته ولعًا بالحرية والحياة (رحيم، ترنيمة امرأة..شفق البحر، 2012) هذه ونه المرأة الحبيبة التي منحت (سامر)

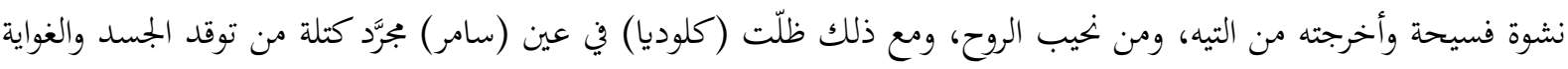

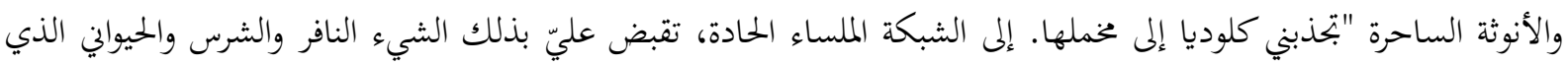

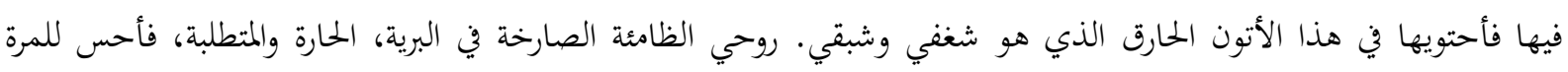

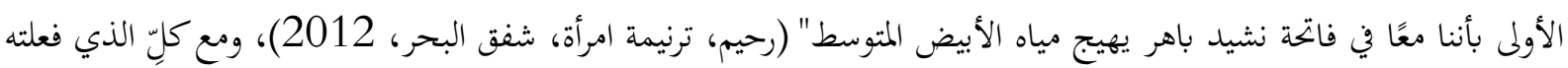

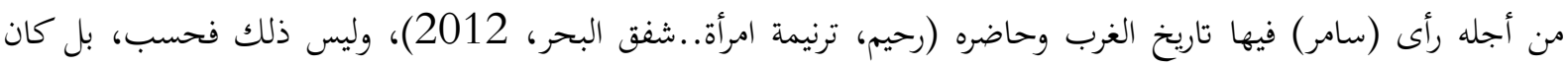

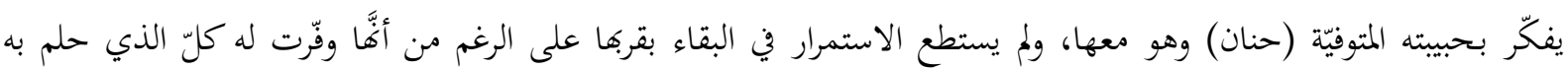

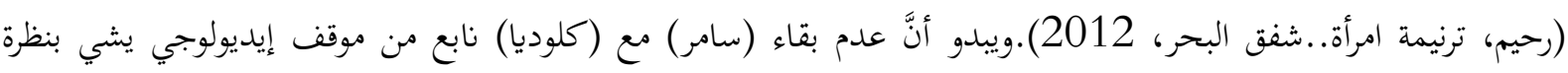

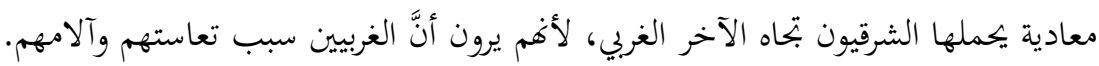

وفي رواية (فسحة للجنون) نلحظ قصة حبّ بين (عامر /حكمت) و(هلة)، لكنّ هذه الحبيبة كانت في نظر حبيبها مجرد موضوع للوحة فنيّة، فهي مجرد موديل وجسد عارٍ جميل يفيض أنوثة وقوة روح، يمكن أن يكون موضوع لوحة تبهر العالم وبتعل

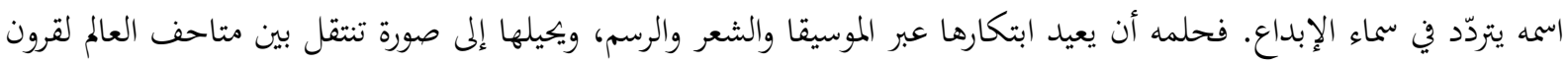

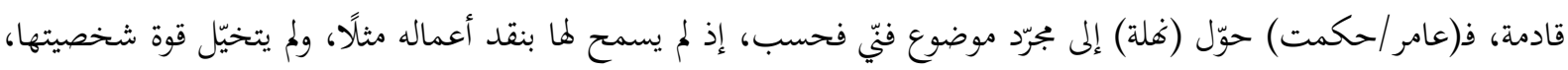

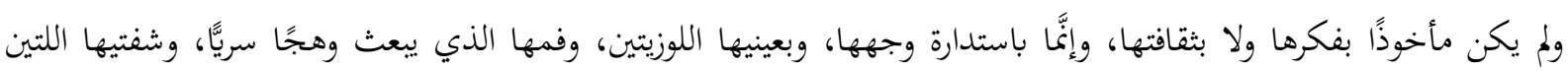

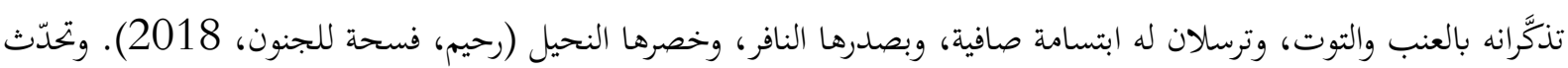

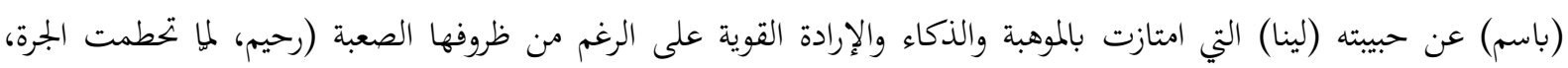

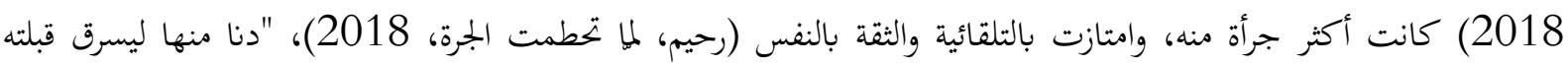

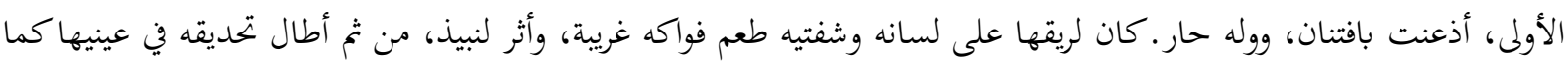
لو أنّ في شرفة يطل على الفردوس، مع ست قبل أخرى بدا أن الحياة تختلج بين ساعديه، تعطيه أبهى ما عندها" (رحيم، لما

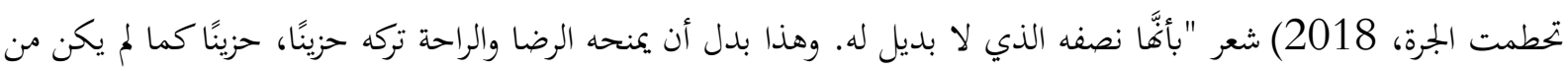

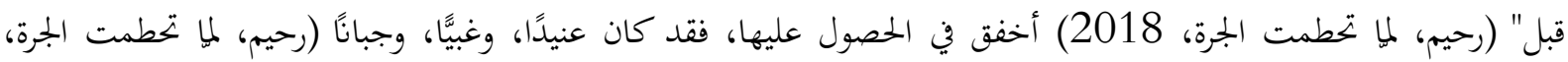

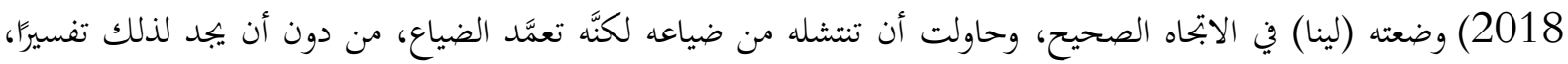

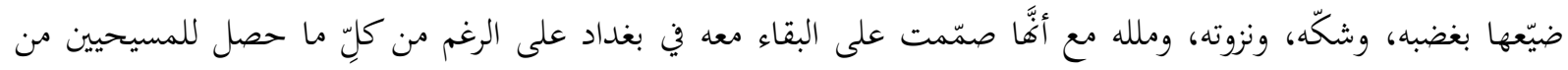

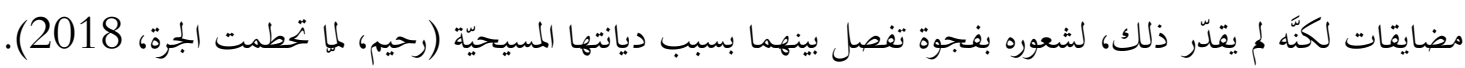


ولم تكن (ناتاشا) بأفضل حالٍ من (لينا)، فقد وقعت ضحية حبّها لـ(محود المرزوق) الذي لوّنت حياته، وانتشلته من

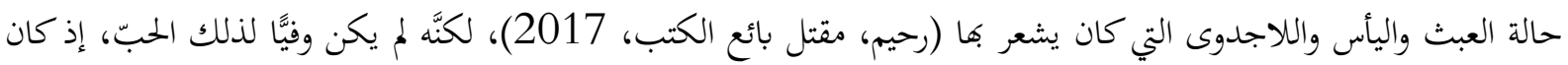

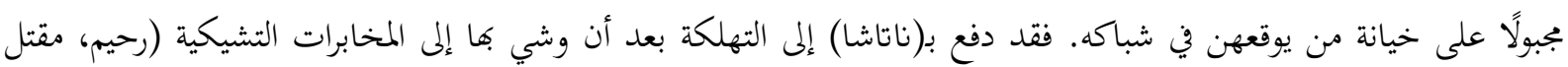

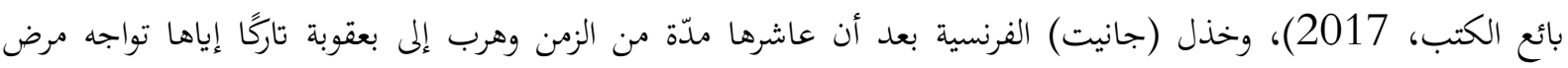
السرطان والعوز (رحيم، مقتل بائع الكتب، 2017)، وقبل ذلك تسبّب بمقتل ابنة الفلاح ذات السبعة عشر ربيعًا، استدرجها

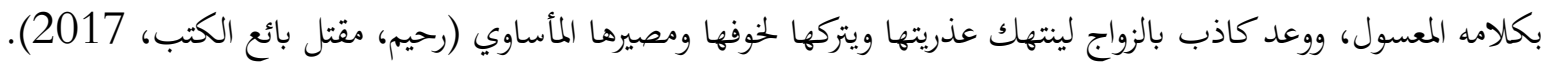

2- 20 - 2 - الحبيبة المعطوبة

أعني هما الحبيبة المعطوبة جسديَّا بسبب المرض، ومن تمظهرات هذا النمط (حنان) وهي فتاة من الديوانية، تعرَّف عليها

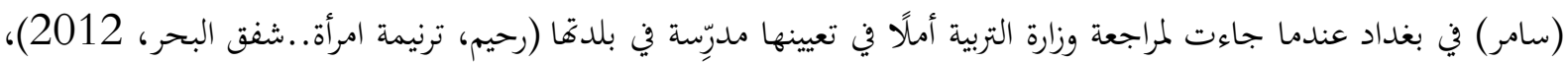

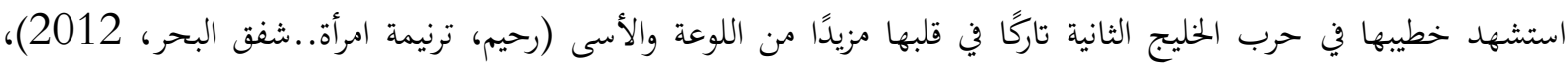

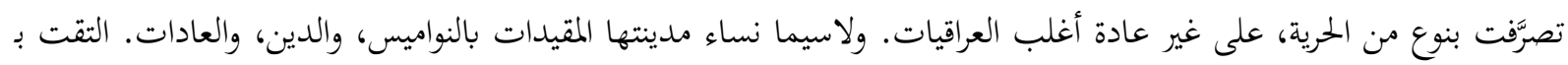

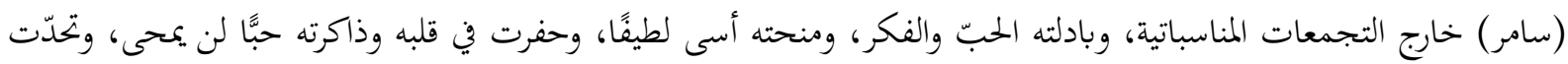

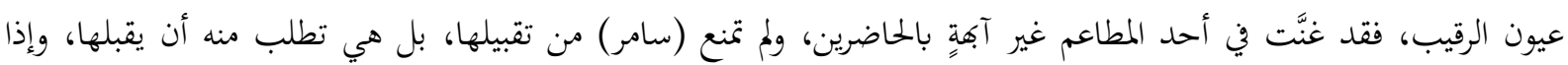

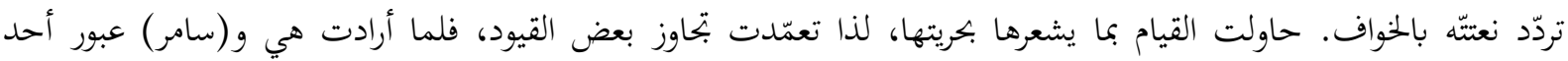

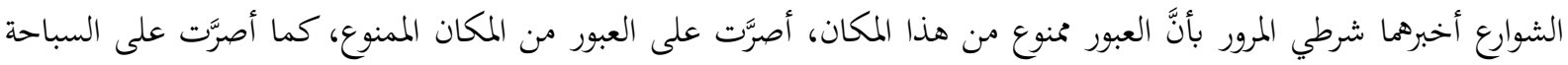

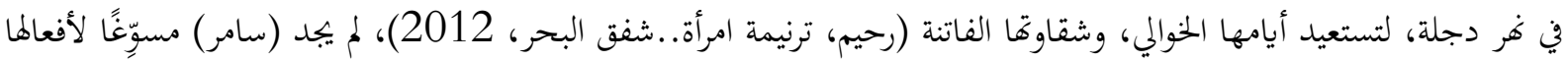

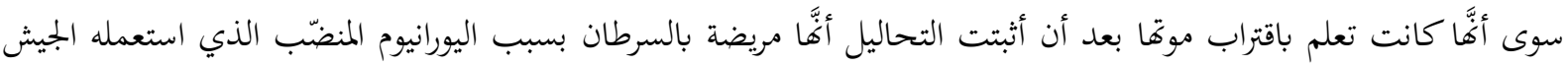

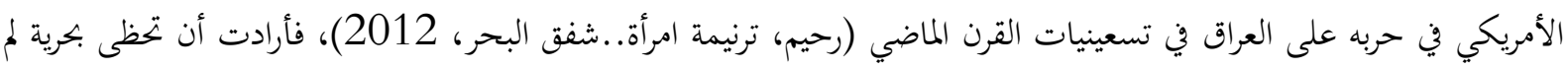

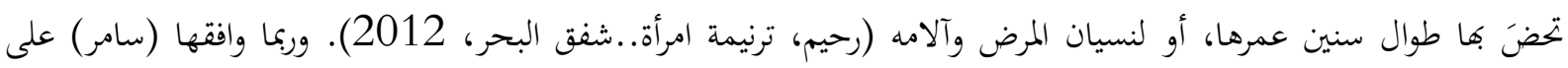

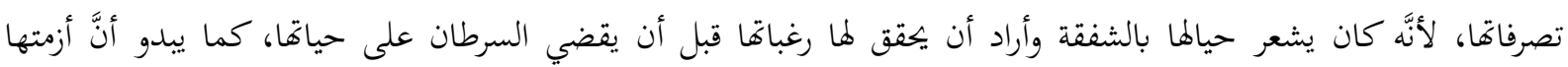

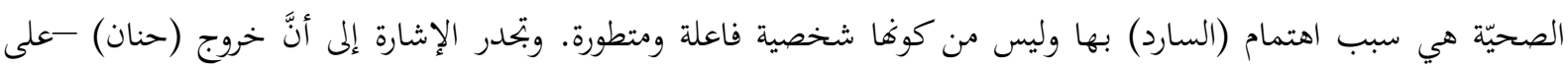
الرغم من انتمائها لبيئة محافظة- للبحث عن عمل هو مؤشر على استجابة المجتمع وتعاطيه الإيجابي مع قضية خروج المرأة وممارستها

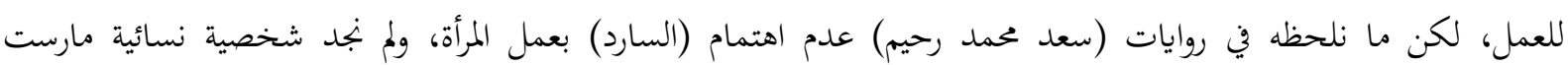
تخصصها بشكل فاعل في هذه الروايات.

لم يكن التقدم في العمر مانعًا (رمزي)، و (هانا) من الذوبان في عوالم الحبّ واقتناص اللحظات السعيدة من بين براثن الزمن

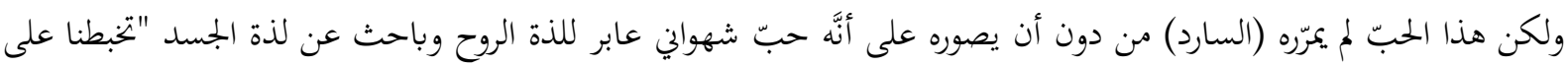

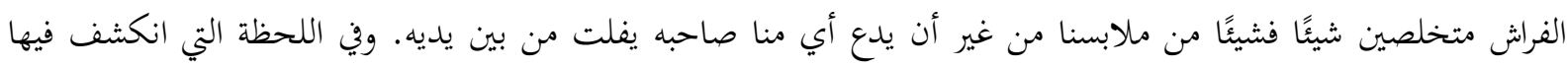

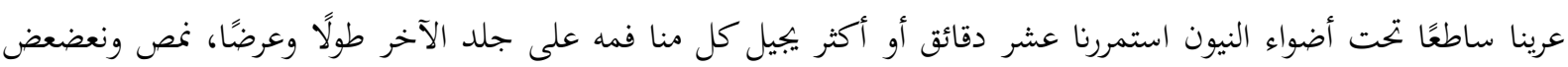

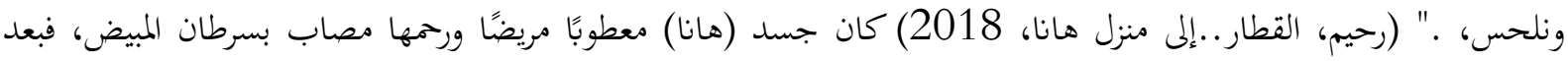

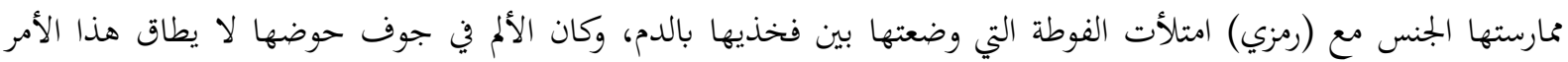

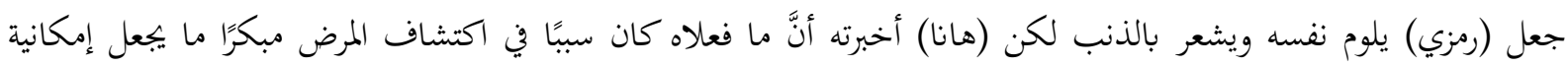

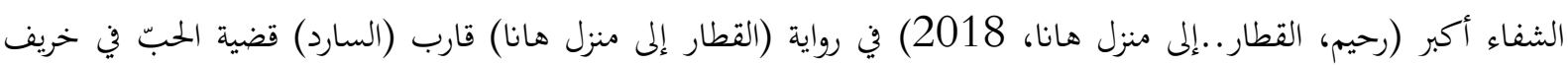

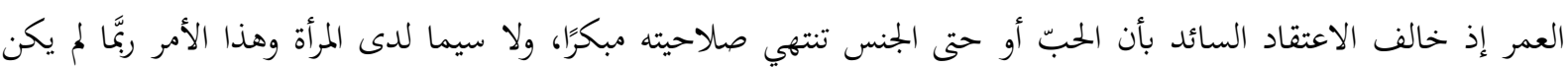


ليحصل لو كان في غير البيئة التي جرت فيها أحداث الرواية، فالبيئة والمجتمع هما من سمح لـ(هانا)، و(رمزي) بهذا التقارب وعيش الحيش تجربة الحبّ في أخريات العمر.

\section{3- 3 الحبيبة اللعوب أو المتقلّبة}

وأقصد بها المرأة التي تتلاعب بمشاعر الرجل وتسعى للتقرب منه حتى إذا ما تمكّنت من قلبه تخلّت عنه وبحثت عن آخر، وبذلك تفقد هويتها ومصداقيتها وتعيش في صراع مع ذاتما، من نماذج هذا النمط (مها) وهي طالبة جامعية، تنتمي لعائلة ثرية إدية

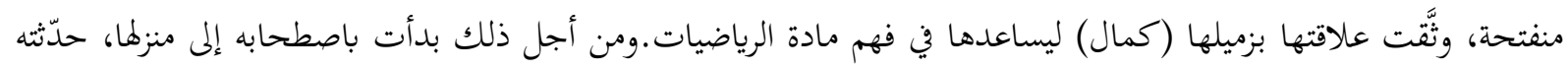

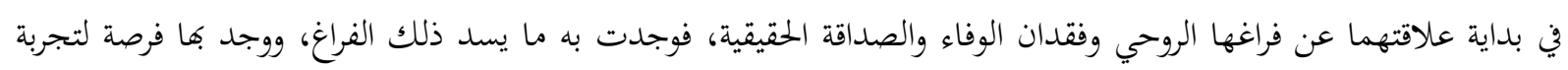

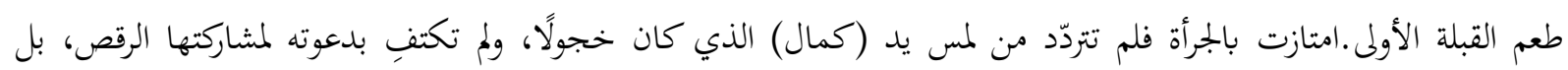

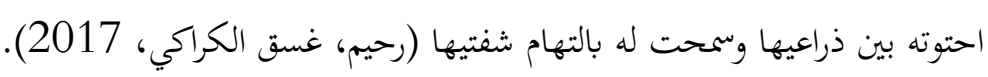
لقد عملت الرواية على إظهار (لينا) قليلة الفهم، فهي بتحيد الرقص ولكنها لا بحيد فهم الرياضيات، كما ظهرت بصورة

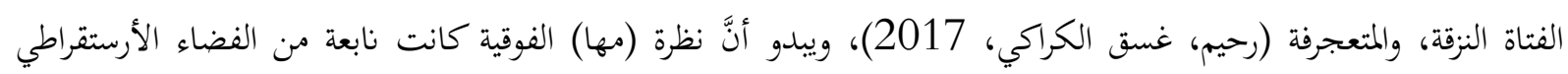

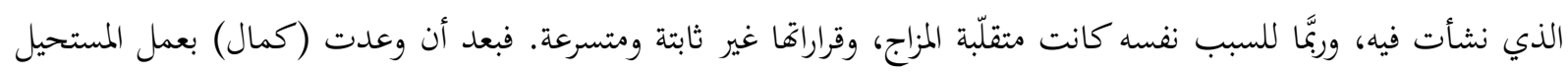

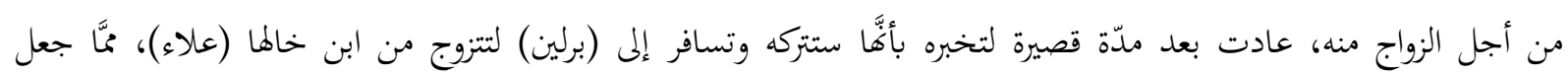

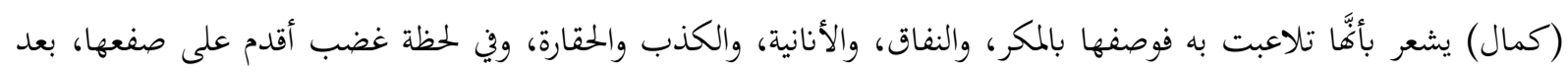

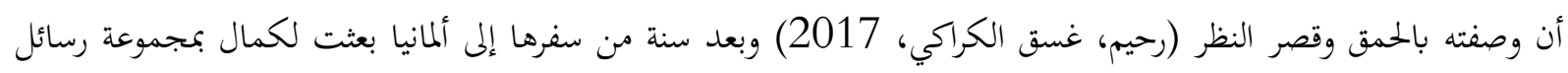

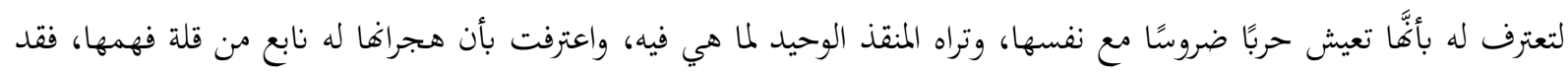

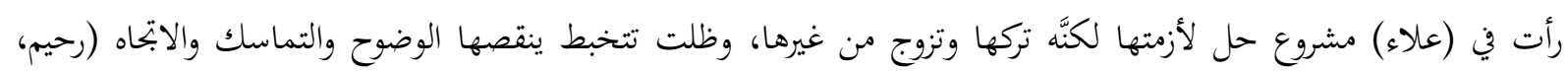

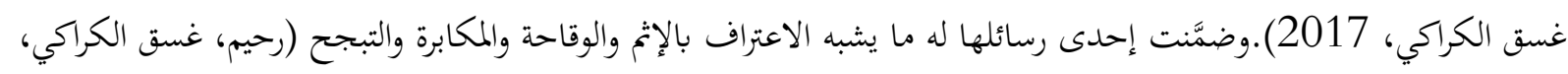

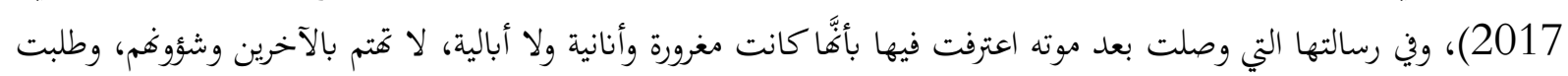

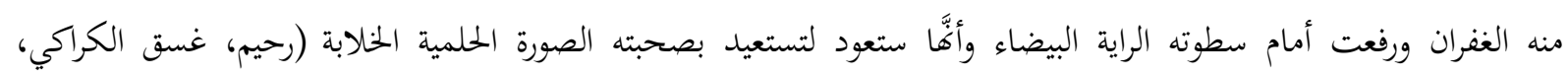

لقد كشفت شخصية (مها) عن سطحيّة المرأة الارستقراطية وتعاليها وشعورها بالضياع والتوهان، وعدم مشاركتها أبناء

مجتمعها معاناتم وقضاياهم.

من الواضح أنَّ معشوقات (كمال) جميعهن متقلبات لا يثبتن على حال، وهذا ما كشفته مذكراته إذ إنَّه تعرَّف مصادفة

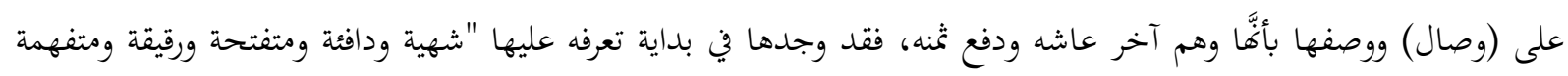

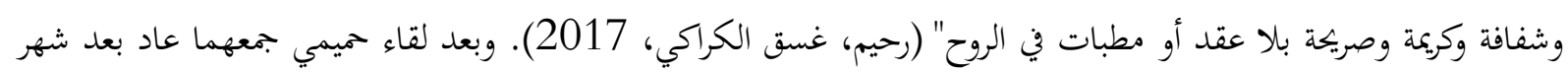

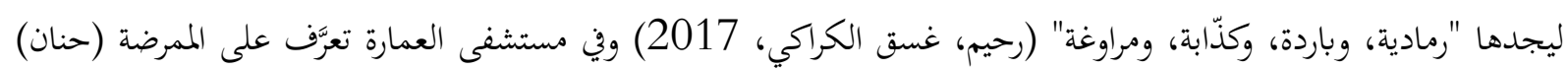

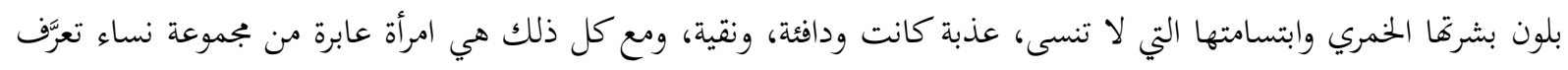

$$
\text { عليهن (رحيم، غسق الكراكي، 2017). }
$$

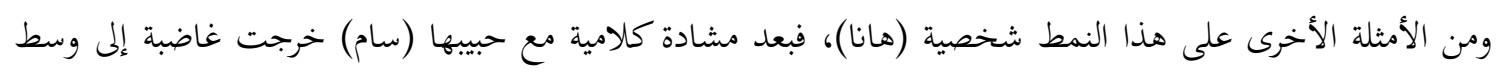

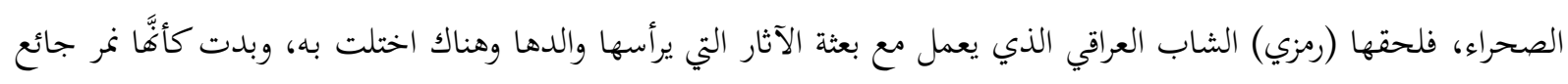

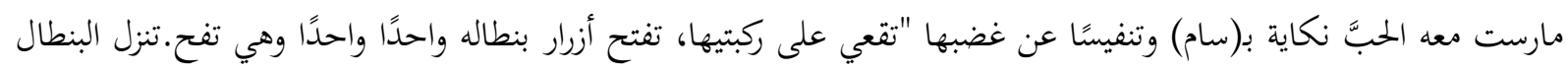

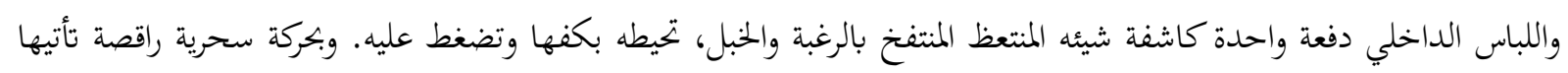


يجد نفسه وقد انزلق فيها. وإذ يروح جذعها يهتز صاعدًا نازلًا عليه كفارسة منطلقة على حصاها في الريح بألف روح والجة في

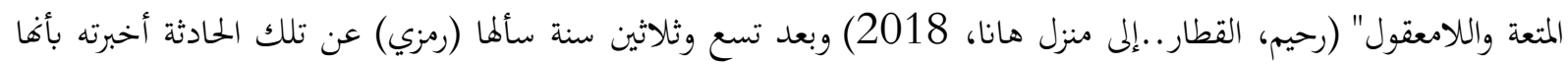

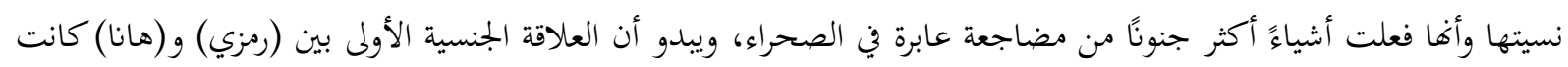

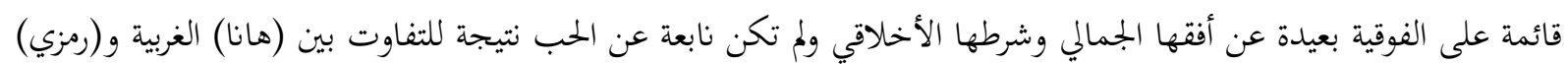

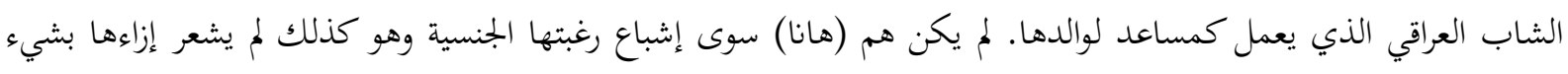

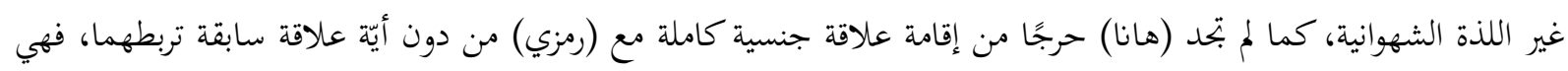

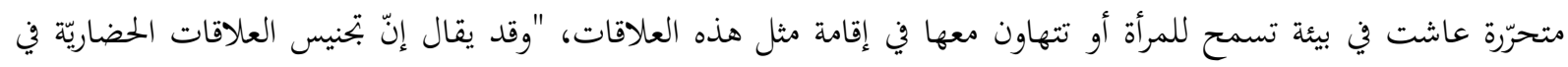

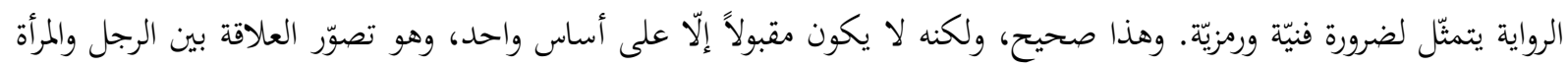

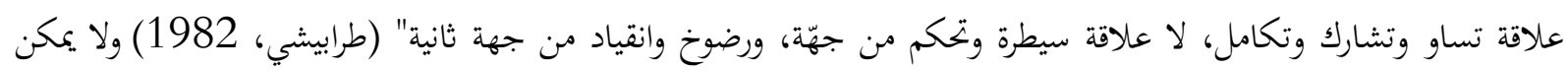

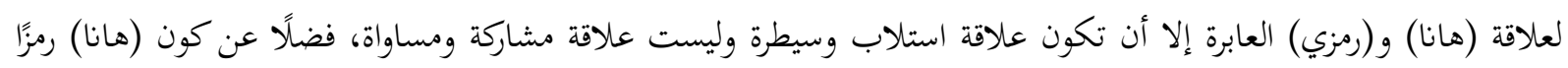

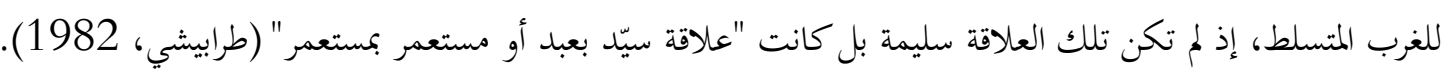

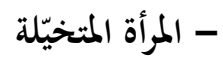

جاء في مذكرات (كمال) أنّه تختيّل وهج النور في الساحة الخلفية للفندق كما لو أنَّه امرأة رآها من نافذة غرفته، "أو ظل

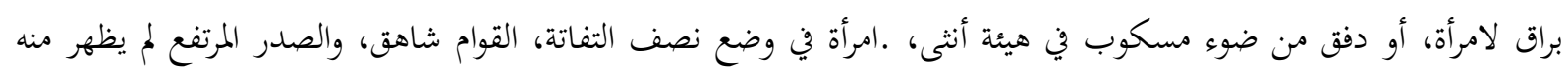

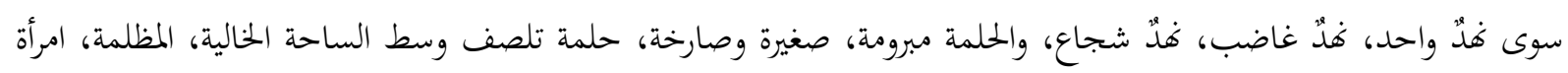

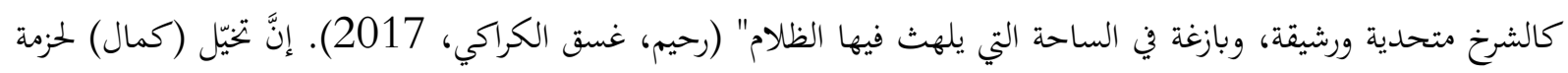

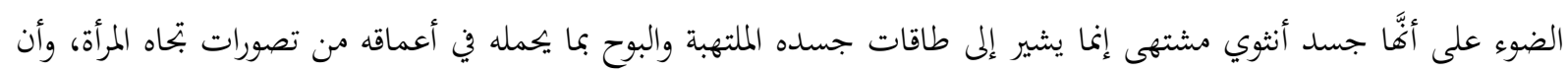

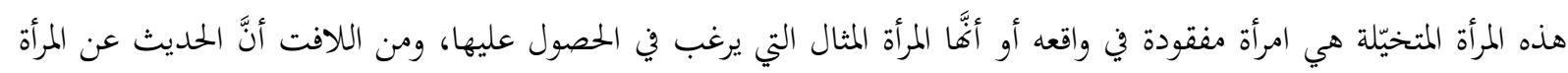

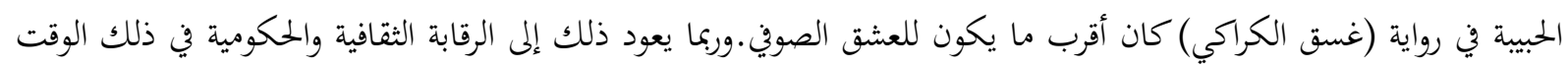

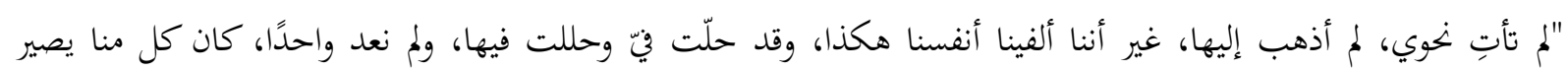

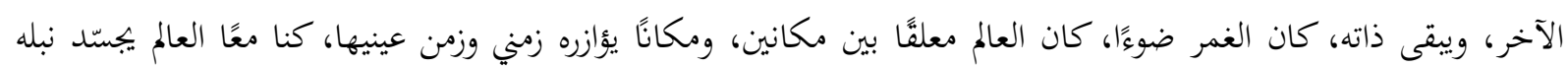

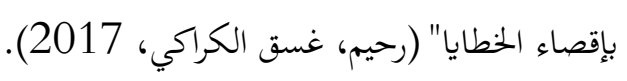

لقد شكّلت المرأة المتخيّلة أو المحلوم بها صورة موازية للمرأة الواقعية ومتنفّسًا للرجل غير القادر على نواها في الواقع -أو

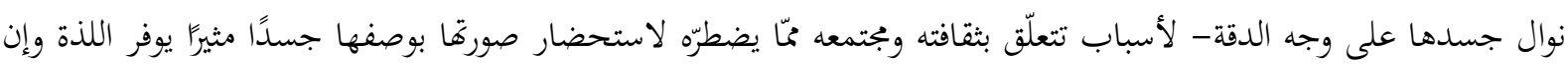

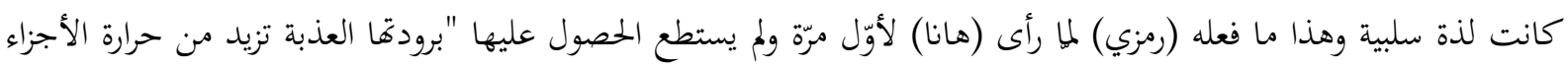

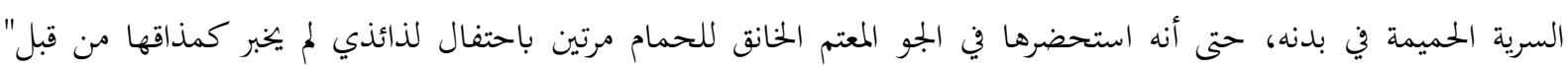
(رحيم، القطار ..إلى منزل هانا، 2018).

لقد عالجت هذه الروايات قضية الحبِّ على نحو يشي بأهمية هذه القضية المرتبطة بعاطفة الإنسان وطبيعة تكوينه ولكن ما

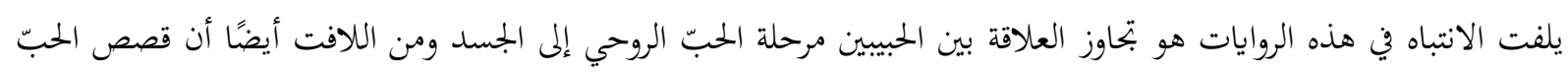

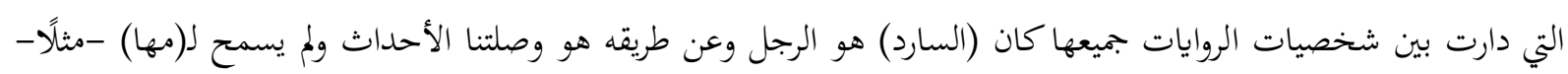

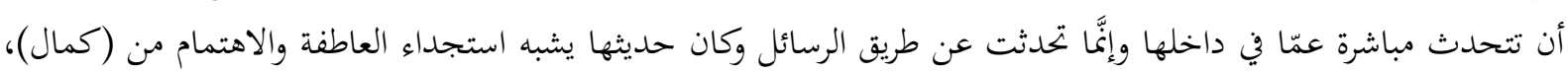

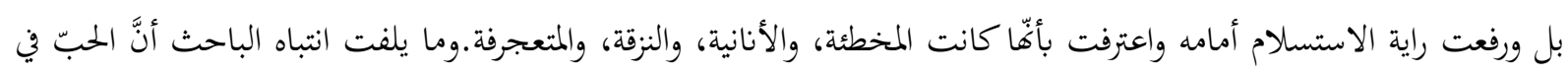


روايات (سعد محمد رحيم) اختلط بالجنس، فبعد قراءة الروايات لم نجد رواية فصلت بين الحبّ والنظرة الشهوانية للجسد، كما

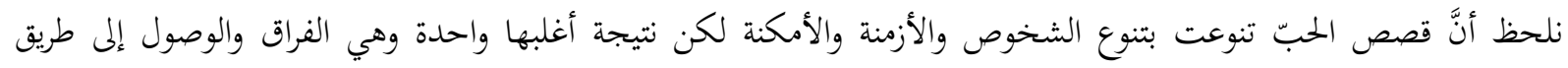

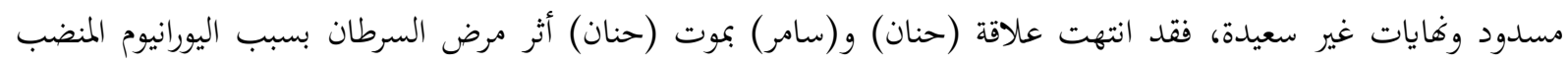

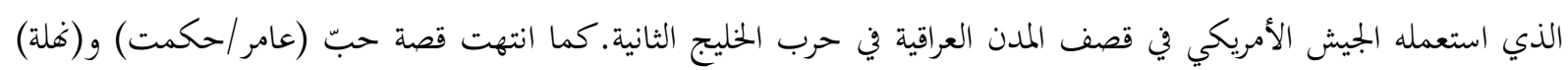

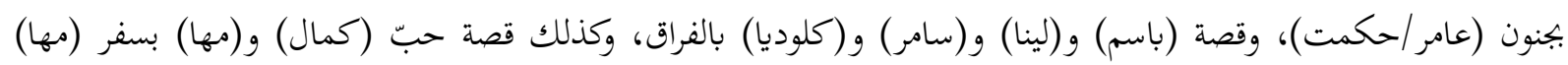

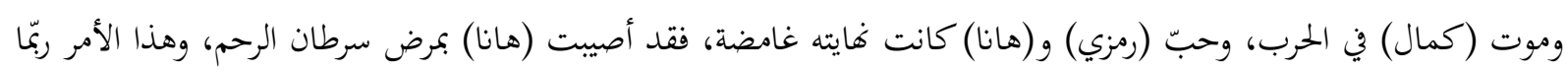
يشير إلى نظرة (السارد) التشاؤمية للمستقبل.

- المرأة الجسسد

للجسد في الرواية علاقة متينة بطرح أسئلة العلاقة بين المرأة والرجل وقد "عمدت كثير من النصوص الروائية العربية إلى

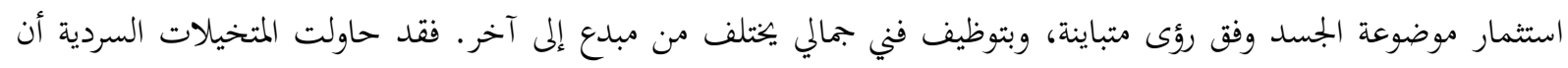

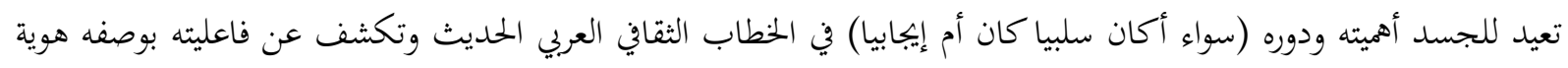
ثقافية ملغزة" (النعيمي، 2007).

لقد طفحت روايات (سعد محمد رحيم) -ماعدا رواية غسق الكراكي- بمشاهد جريئة جلًا صوّرت الجسد بكامل تفصيلاته، ولم يتحرّج (السارد) من وصف العلاقات الجنسية تلك التي تقع ضمن المسكوت عنه سواءً التي حصلت في إطار

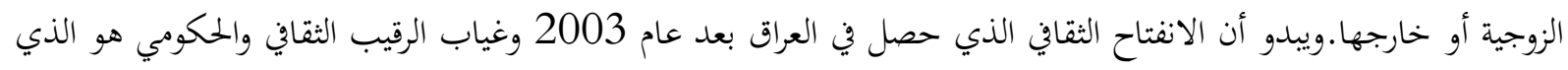

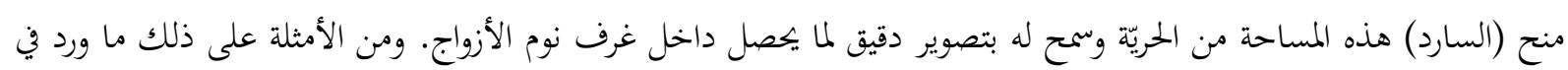

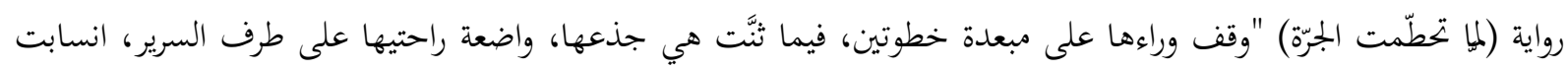

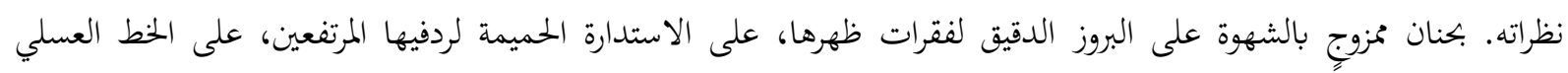

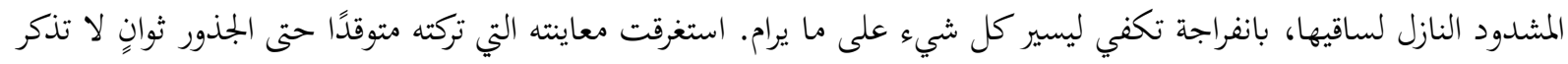

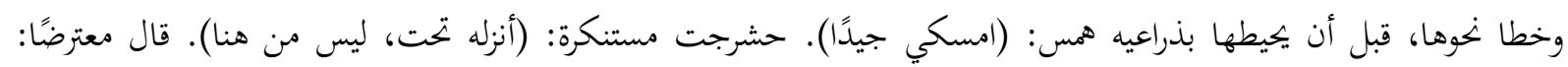

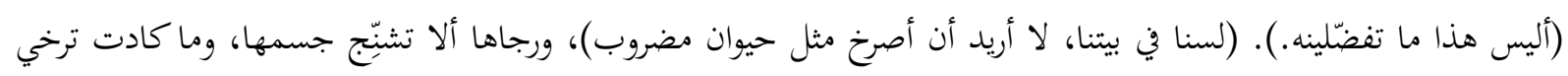

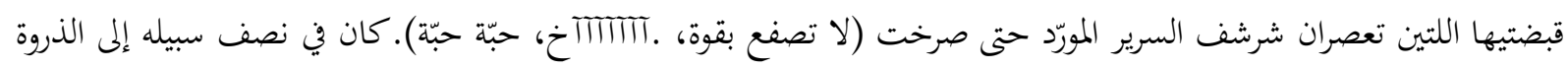

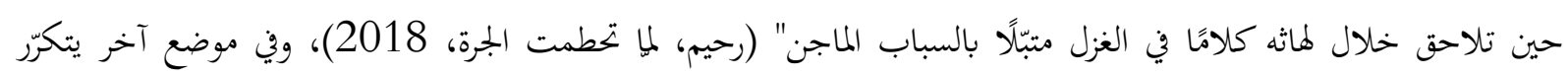

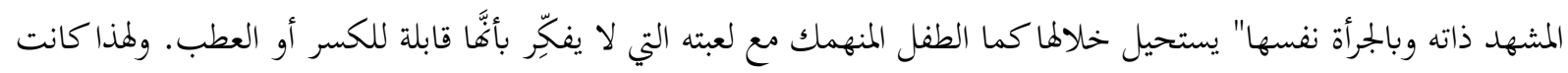

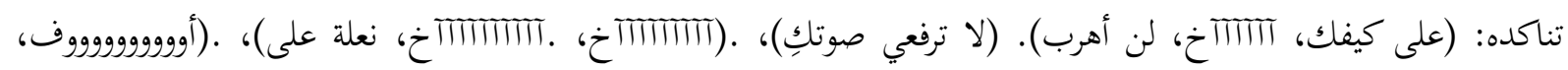

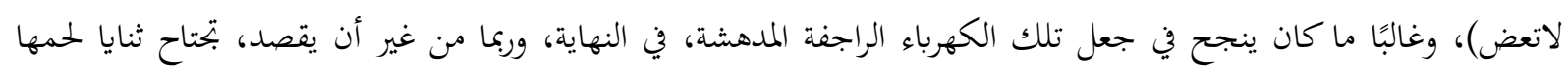

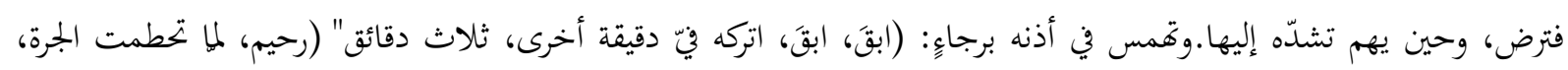

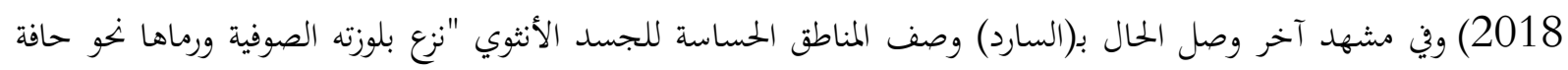

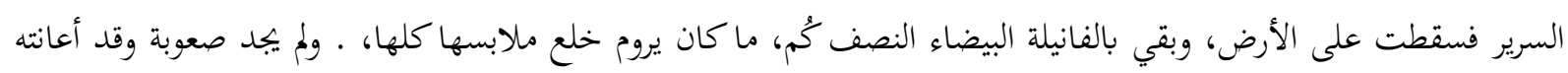

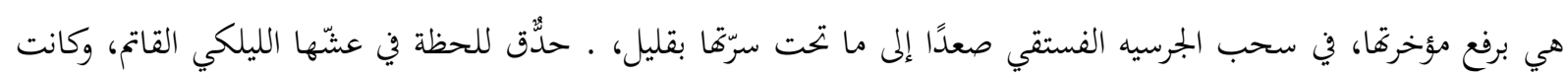
تعرف أنه يفضّل الإبقاء على هذه المتاهة المثيرة من الشعر الخشن الكثيف" (رحيم، لما تحطمت الجرة، 2018) 
إن وصف المشاهد الجنسية بما فيها من حركات وأصوات مثيرة ربمّا يكون المدف من ورائها جذب القارىء، وتسويق الرواية، أو يكون الهدف منها تحطيم القيود والأعراف تماشيًا مع دعوات ما بعد الحداثة، ويبدو أن الجسد بصفة معنة عامة "في الفضاء

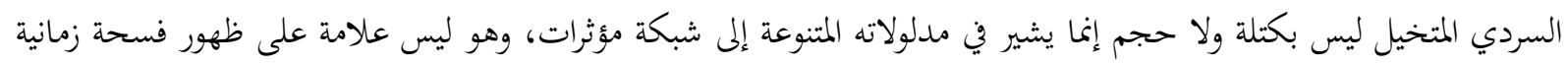

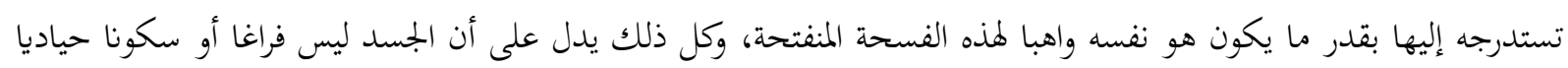

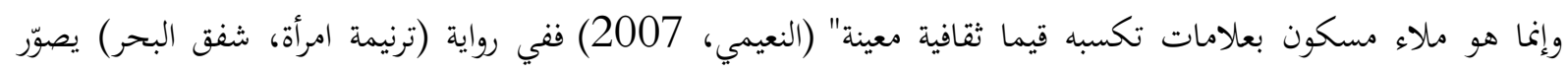

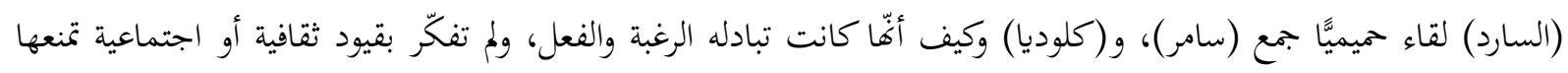

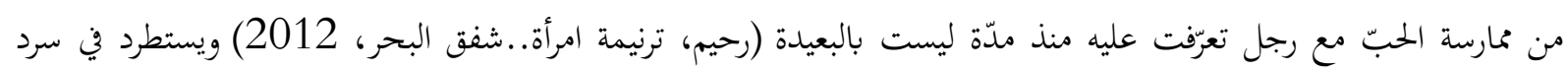

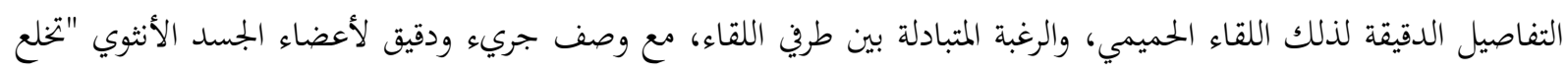

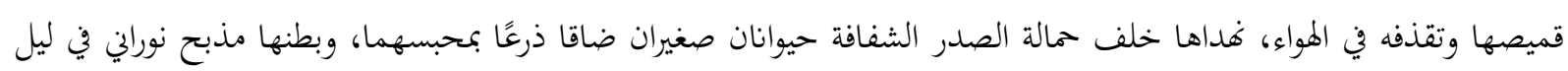

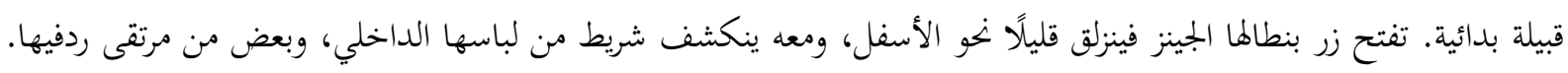

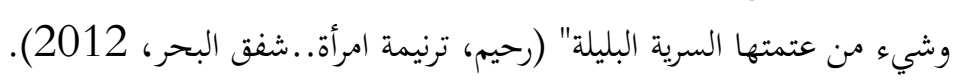

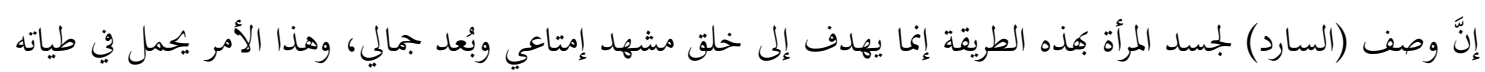

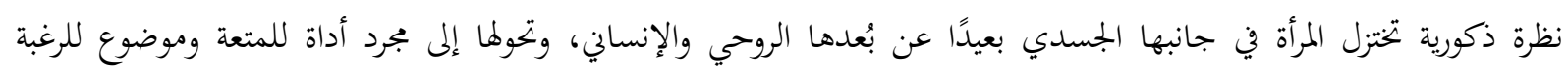
والإثارة.

\section{المرأة المومس}

قد يلجأ (السارد) إلى توظيف شخصية ما ومنها الشخصية المتهتكة، لتحقيق أهداف كتابية فقد "تشكّل الشخصية

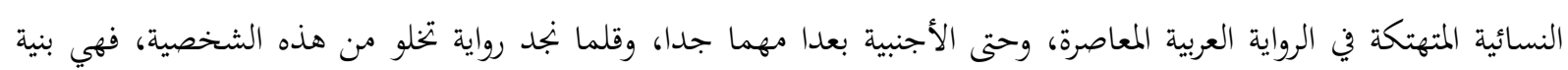

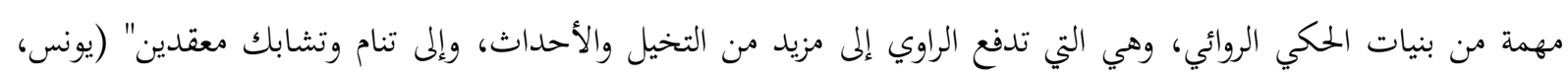

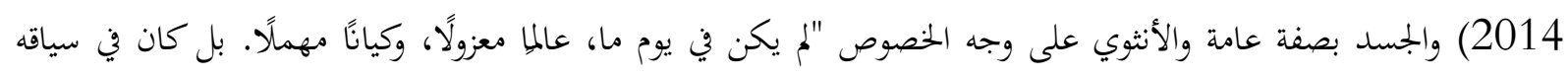

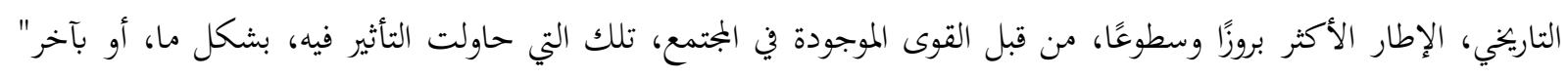

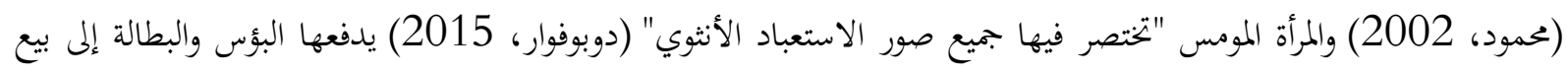

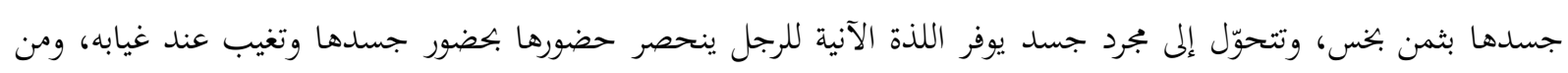

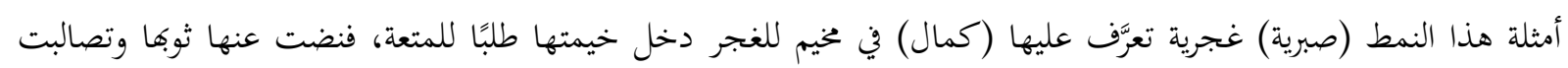

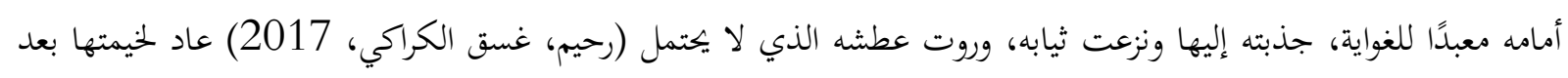

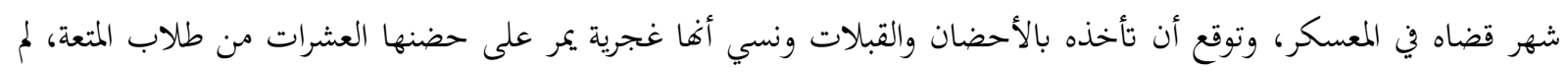

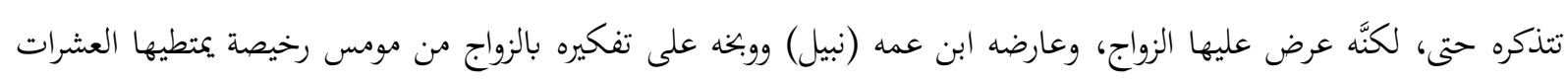

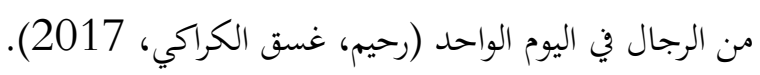

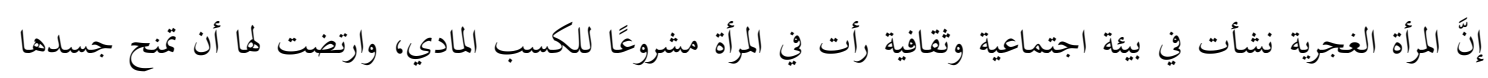

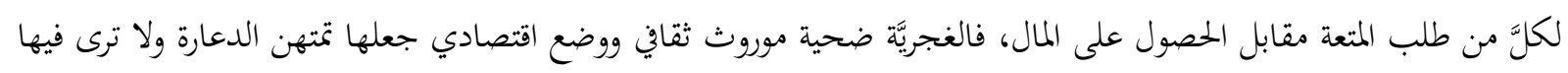

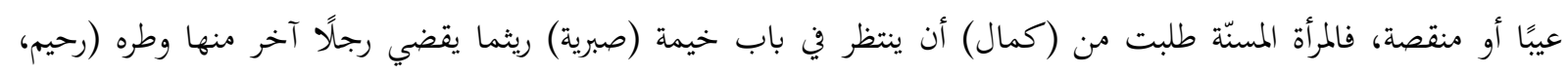
غسق الكراكي، 2017).

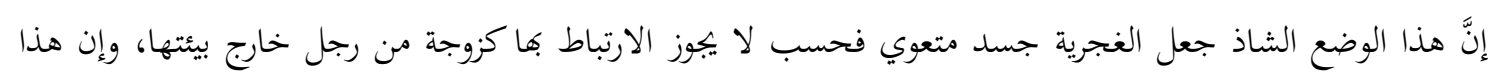

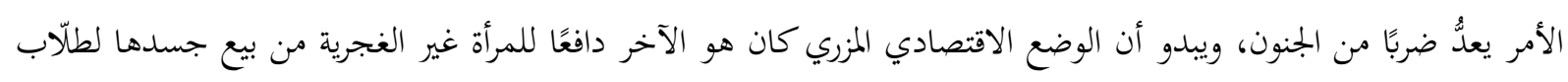

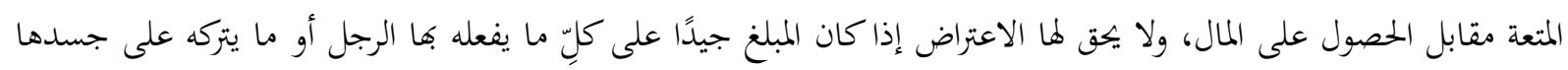


وهو في قمة نشوته الجنسية من آثار وكدمات نتيجة الضرب أو العض، فضلًا عن الشتائم والألفاظ المهينة، ليجعلها باكية تستدر

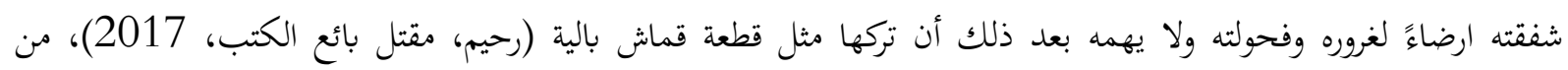

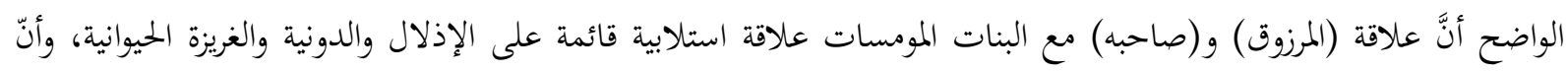

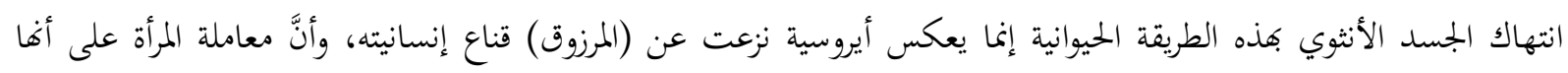

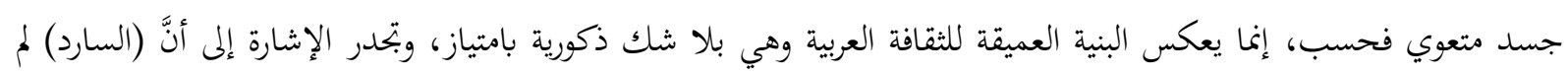

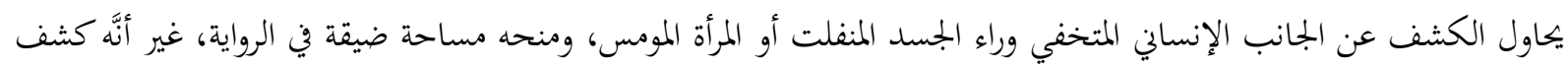

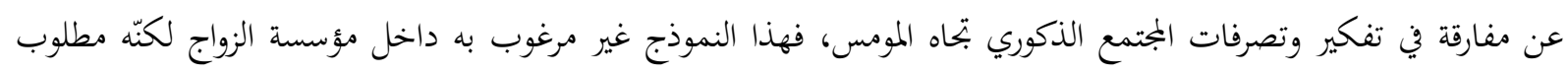
بشدة خارج أسوارها.

\section{الخاتمة ونتائج البحث}

- لم يمنح (السارد) مساحة جيدة لفكر المرأة وأدهما وثقافتها، في حين سجّل جسدها حضورًا طاغيًا في جميع روايات البحث، ولم

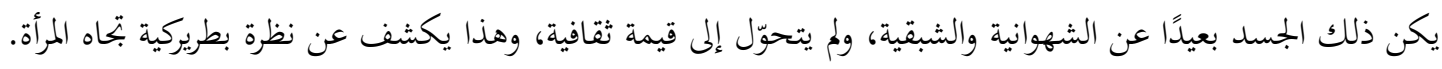

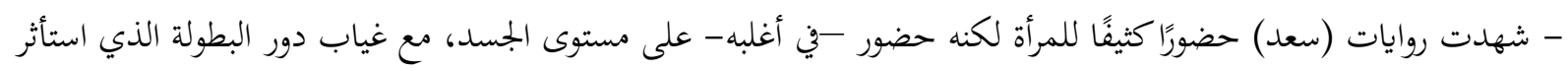
به الرجل فهو الشخصية الرئيسة والمرأة شخصية ثانوية.

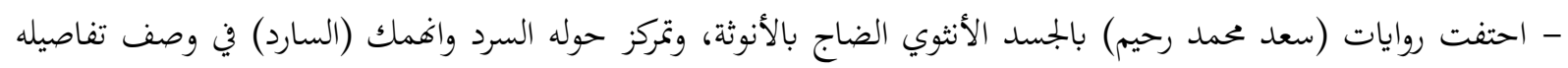
وغالبا ما كان ذلك على حساب الرواية. - حضرت المرأة في أغلب الروايات عاشقة ومعشوقة وإن ظهرت أيضا صبورة مطيعة للزوج وخائنة وأنانية، كما ظهرت أيضا في

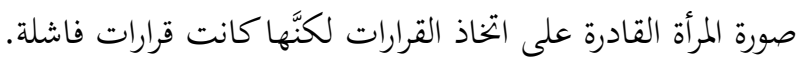
- تنوّع الحبّ في روايات (سعد محمد رحيم) بين حبّ الجسد الأنثوي والحبّ الروحي، ولكن الأول كان طاغيا على جميع الروايات،

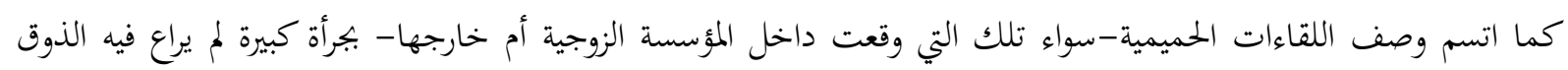

- كل الشخصيات النسائية في روايات البحث لم يكنَّ مؤثرات في محيطهن وغير مهتمات بشأن المجتمع ولا هدف لهنَّ ولا رسالة

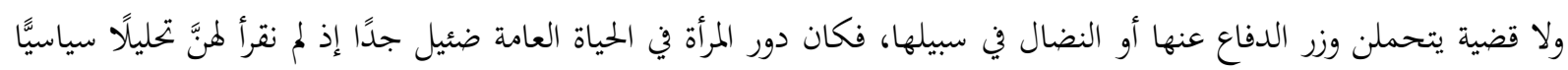

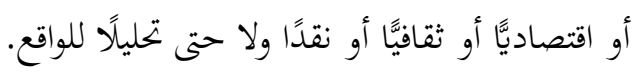
- المرأة عامل مساعد في روايات (سعد) وظل الرجل هو الفاعل وهو السارد يطوّر شخصياته بالطريقة التي يريد، فالنساء في هذه

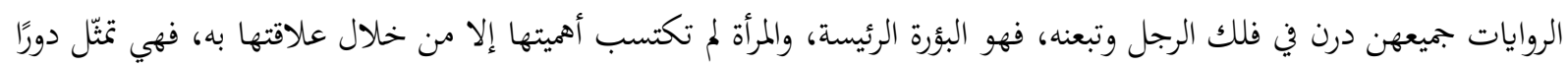

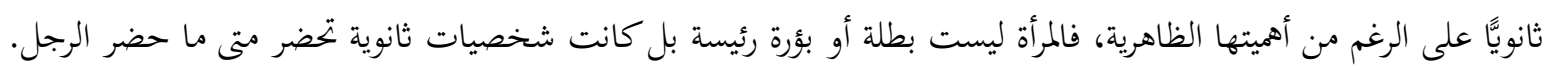
- صورة المرأة في روايات (سعد محمد رحيم) كانت نمطية وهي نتاج معطى ثقافي متجذر ولم تكن صورة جديدة.

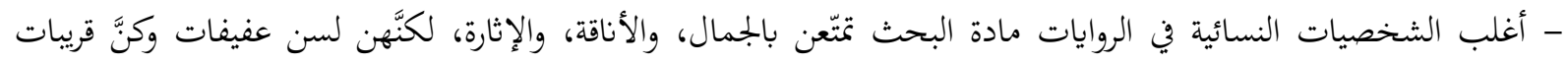
المنال.

- لم يختلف (سعد محمد رحيم) في وصف جسد المرأة عن الشعراء وربما نافسهم في نحت تمثال جسدها وبحميله فقد أبدع في وصفه حسيَّا ولم يترك وصف حتى من مناطقه الحساسة. - تمحورت روايات (سعد محمد رحيم) حول الحرب والحبّ والاحتفال بالجسد من أنوثة وفحولة. 
- في روايات (سعد محمد رحيم) لم تتنوع مهام الشخصيات النسائية ووظائفها التي قامت بها فلا أدوار سياسية ولا دينية ولا اجتماعية مع إشارات تربوية بسيطة اقتصرت على توجيه الأولاد وهذا يدل على سطوة المجتمع الذكوري الأبوي على المجتمع.

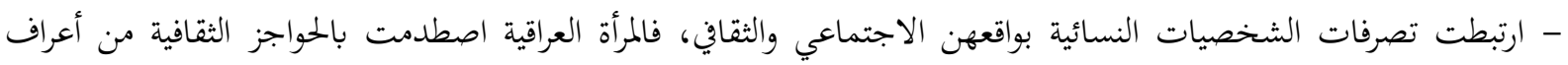

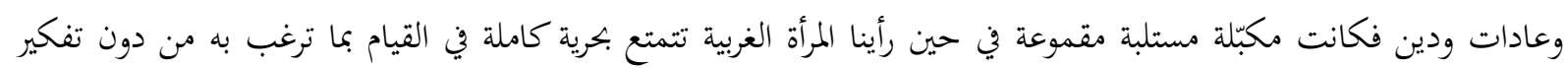
بالقيود والحواجز. - في روايات (غسق الكراكي)، و (فسحة للجنون)، و(ترنيمة امرأة، شفق البحر) نلحظ أنَّ المرأة العراقية في العقود الأخيرة

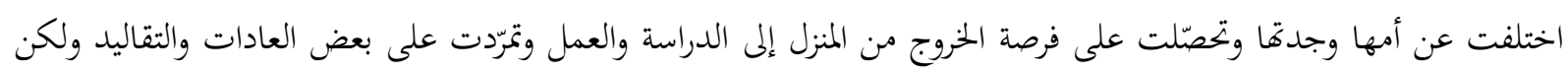

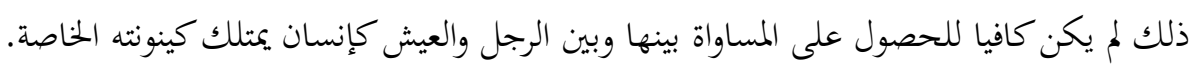

مراجع

إبراهيم محمود. (2002). جماليات الصمت في أصل المخفي والمكبوت (البملد 1). دمشق، سوريا: مركز الإنماء الحضاري. إيمان القاضي. (1992). الرواية النسوية في بلاد الشام (المجلد 1). دمشق: الأهالي للطباعة والنشر والتوزيع.

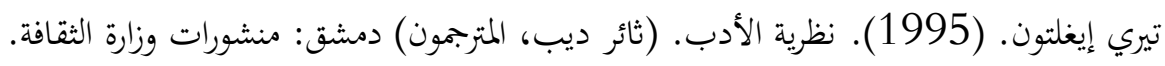

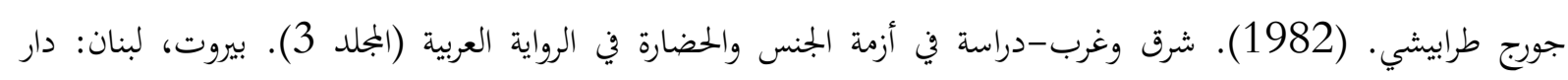
الطليعة.

حسن بحراوي. (1990). بنية الشكل الروائي (المجلد 1). بيروت، لبنان: المركز الثقافي العربي.

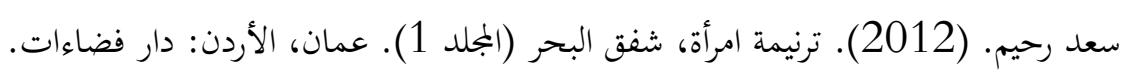

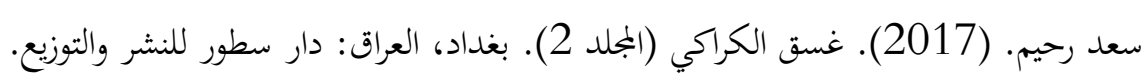

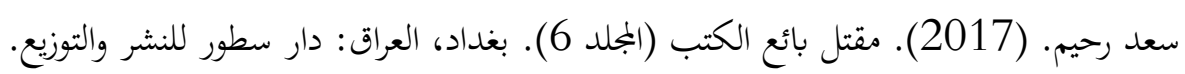

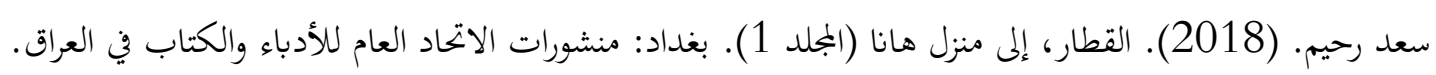
سعد رحيم. (2018). فسحة للجنون (المجلد 1). بغداد، العراق: دار سطور للطباعة والنشر.

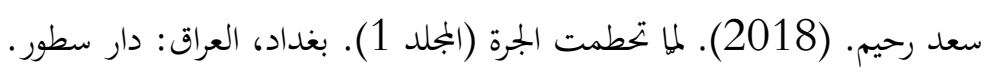

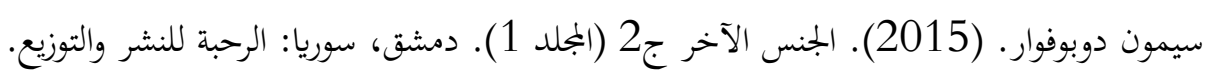

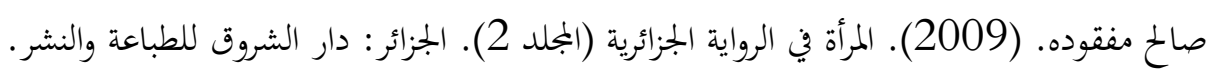

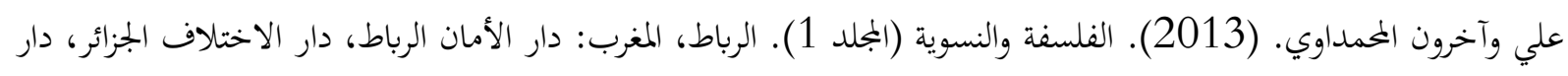

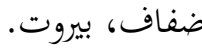

فيصل النعيمي. (23- 24 آيار, 2007). تسويق الجسد بين المتعة والنسق الثقافي مقاربة لرواية: خطوط الطول، خطوط

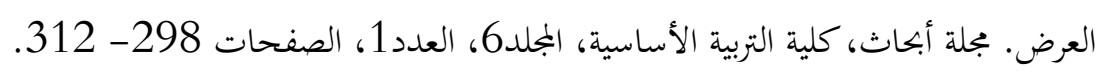

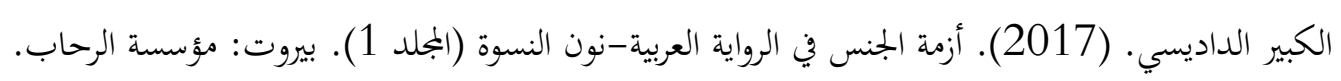
محمد عبدالمطلب. (2008). ذاكرة النقد الأدبي (المجلد 2). القاهرة: المجلس الأعلى للثقافة. محمد الغذامي. (2006). المرأة واللغة (المجلد 3). الدار البيضاء، المغرب: المركز الثقافي العربل العربي.

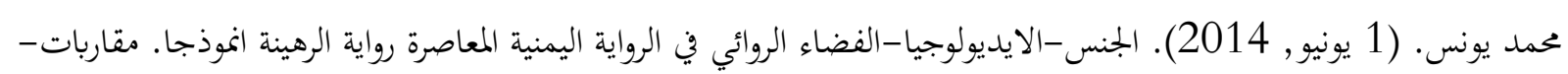
بجلة العلوم الانسانية، الصفحات 5- 36. 